\title{
Influence of the Co/Ni Ratio and Dendritic Segregations on the High-Temperature Oxidation Resistance of Multinary Co-Rich Superalloys at $850{ }^{\circ} \mathrm{C}$ and $1050^{\circ} \mathrm{C}$
}

\begin{abstract}
S.P. HAGEN, M. WEISER, B. ABU-KHOUSA, and S. VIRTANEN
Excellent inherent oxidation resistance is a prerequisite for the use of superalloys in many high-temperature applications. To achieve this goal, typically continuous alumina and chromia scale growths are assured through sufficient $\mathrm{Cr}$ and $\mathrm{Al}$ additions. Since the intended $\gamma /$ $\gamma^{\prime}$-microstructure of superalloys is only stable within a certain compositional window, the maximum concentrations of these protective scale forming elements are, however, dependent on the overall alloy composition. The latter is a severe drawback, especially for Co-rich superalloys, as for these the maximum content often is insufficient for reaching the desired continuous scale growth. In recent years, the addition of significant $\mathrm{Ni}$ levels was identified to improve the high-temperature oxidation properties in the case of simple model alloy systems. In this study, we compare the high-temperature oxidation behavior of two complex Co-rich multinary single-crystalline $\gamma / \gamma^{\prime}$-strengthened superalloys that only differ regarding their $\mathrm{Co} / \mathrm{Ni}$ ratios to the commercial Ni-base superalloy CMSX-4. Therefore, time-resolved isothermal gravimetric analysis (TGA) in synthetic air at $850{ }^{\circ} \mathrm{C}$ and $1050{ }^{\circ} \mathrm{C}$ for 100 hours, scanning electron microscopy analysis (SEM), and electron probe microanalysis (EPMA) were conducted. The results point out that a high Co-content beneficially affects the oxidation resistance at $850{ }^{\circ} \mathrm{C}$, meaning that the Ni-base CMSX-4 is slightly outmatched by the Co-rich competitors. In contrast, at $1050{ }^{\circ} \mathrm{C}$, the commercial (most Ni-rich) alloy performed best and, clearly, an increasing Co-content was identified to deteriorate the oxidation resistance. This temperature-dependent influence of the nominal $\mathrm{Co} / \mathrm{Ni}$ ratio on oxidation resistance is shown to be especially pronounced for dendritic regions. Consequently, the latter could be identified to especially determine the overall oxidation kinetics.
\end{abstract}

https://doi.org/10.1007/s11661-022-06620-6

(C) The Author(s) 2022

\section{INTRODUCTION}

THE advanced multinary single crystal Co-base superalloy ERBOCo-1 with remarkable high-temperature properties above $1000{ }^{\circ} \mathrm{C}$ was recently introduced. ${ }^{[1]}$ Among others, the long-term stability of the two-phase microstructure is especially beneficial for usage at elevated temperatures. Selecting and carefully balancing 9 alloying elements lead to intriguing creep behavior under tensile and compressive loading ${ }^{[2]}$ as well as adequate resistance against corrosion. ${ }^{[1]}$

S.P. HAGEN, B. ABU-KHOUSA, and S. VIRTANEN are with the Chair for Surface Science and Corrosion (Insitute IV), FriedrichAlexander Universität Erlangen-Nürnberg, 91058 Erlangen, Germany. Contact e-mail: sebastian.p.hagen@fau.de M. WEISER is with the Chair for General Materials Properties (Institue I), FriedrichAlexander Universität Erlangen-Nürnberg, 91058 Erlangen, Germany. Manuscript submitted November 15, 2021; accepted January 26, 2022. Article published online February 16, 2022
In recent years, extensive research activities to further optimize the phase stability of two-phase $\mathrm{Co}-\mathrm{Al}-\mathrm{W}$ based superalloys, originally reported by Sato et al. ${ }^{[3]}$ were driven by the aim to compete with commercial Ni-base Superalloys. Nevertheless, a considerable amount of $\mathrm{Ni}$ in the multinary Co-base alloys remains indispensable to ensure phase stability. ${ }^{[4-8]}$ Our studies on the oxidation behavior of Ni-free Co-base model alloys led to similar conclusions. ${ }^{[9,10]}$ Although the growth of a continuous diffusion-limiting alumina layer could be triggered by shot-peening, the decay of the two-phase microstructure beneath the oxide scale due to Al-depletion remains one apparent drawback. The oxidation resistance at $900{ }^{\circ} \mathrm{C}$ significantly improves, if the ratio of Co to Ni decreases. ${ }^{[11-13]}$ The reversed trend was, however, found for exposure of two-phase $\mathrm{Co} /$ Ni-base model alloys at $800{ }^{\circ} \mathrm{C} \cdot .^{[11,14]}$

Like for conventional Ni-base superalloys, the applicability of these novel Co-base alloys with considerable $\mathrm{Ni}$ levels relies on coatings to guarantee their durability 
Table I. Nominal ${ }^{[1,24]}$ and Actual Elemental Compositions of the Alloys ERBOCo-1 and ERBOCo-1X in At. Pct as Well as Respective Co/Ni Ratios, Determined by ICP-OES in AC State

\begin{tabular}{|c|c|c|c|c|c|c|c|c|c|c|c|}
\hline & Alloys & Co & $\mathrm{Ni}$ & $\mathrm{Al}$ & $\mathrm{Cr}$ & W & $\mathrm{Ti}$ & $\mathrm{Ta}$ & $\mathrm{Si}$ & $\mathrm{Hf}$ & $\mathrm{Co} / \mathrm{Ni}$ \\
\hline \multirow[t]{2}{*}{ Nominal } & ERBOCo-1 & 44.5 & 32 & 8.00 & 6.00 & 5.00 & 2.50 & 1.50 & 0.40 & 0.10 & 1.391 \\
\hline & ERBOCo-1X & 32 & 44.5 & 8.00 & 6.00 & 5.00 & 2.50 & 1.50 & 0.40 & 0.10 & 0.719 \\
\hline \multirow[t]{2}{*}{ Measured } & ERBOCo-1 & 45.01 & 32.45 & 7.86 & 5.90 & 4.99 & 2.12 & 1.4 & 0.18 & 0.09 & 1.387 \\
\hline & ERBOCo-1X & 32.34 & 45.42 & 7.72 & 5.93 & 4.85 & 2.07 & 1.37 & 0.20 & 0.09 & 0.712 \\
\hline
\end{tabular}

Measurement uncertainties are \pm 0.15 for $\mathrm{Co}$ and $\mathrm{Ni}, \pm 0.05$ for $\mathrm{Al}, \pm 0.07$ for $\mathrm{W}, \pm 0.03$ for $\mathrm{Ti}, \pm 0.05$ for $\mathrm{Cr}, \pm 0.05$ for $\mathrm{Ta}, \pm 0.02$ for $\mathrm{Hf}$, and 0.005 for $\mathrm{Si}$ at most.

during potential applications. Nevertheless, evolution of protective oxide scale sections such as $\mathrm{Cr}_{2} \mathrm{O}_{3}$ or $\mathrm{Al}_{2} \mathrm{O}_{3}$ to ensure adequate intrinsic oxidation resistance in the case of an unexpected degradation of the coatings remains essential. ${ }^{[15,16]}$ These thermally grown oxide (TGO) layers reduce diffusional transport of all reactants due to a particularly low defect density. ${ }^{[17]}$ A suitable example for appropriate oxidation resistance is the widely used commercial second-generation Ni-base alloy CMSX-4 that develops a dense alumina layer at the scale/alloy interface during exposure at $1050{ }^{\circ} \mathrm{C}$ in air. ${ }^{[18-20]}$ In contrast, no protective alumina layer was found in $\mathrm{Co} / \mathrm{Ni}$-base model alloys with significantly higher levels of Co compared to Ni after exposure above $800{ }^{\circ} \mathrm{C} \cdot{ }^{[12,21]}$ However, some alloy compositions indicated the formation of a $\mathrm{Cr}$-containing spinel layer that was demonstrated to slow down oxidation at $900{ }^{\circ} \mathrm{C}^{[11]}$ Addressing a larger compositional window, Stewart et al. identified a promising $\mathrm{Co} / \mathrm{Ni}$-base model alloy that develops a continuous $\mathrm{Al}_{2} \mathrm{O}_{3}$ layer within the first hour of isothermal exposure at $1100{ }^{\circ} \mathrm{C}^{[13]}$ Therefore, the same group distinguished $\gamma^{\prime}$-strengthened superalloys with nearly equal levels of $\mathrm{Co}$ and $\mathrm{Ni}$ as a novel intriguing subclass of high-temperature alloys and commenced with the detailed investigation of elastic constants. ${ }^{[22,23]}$ Nevertheless, our previous investigations of the oxide scale growth on the multinary ERBOCo-1 superalloy ${ }^{[1]}$ indicated that it may be possible to reach comparable oxidation resistance in compositions with higher Co levels compared to $\mathrm{Ni}$ above $1050{ }^{\circ} \mathrm{C}$.

The present study contributes to the characterization of this new advanced Co-base superalloy by a detailed investigation of the oxidation behavior at $850{ }^{\circ} \mathrm{C}$ and $1050{ }^{\circ} \mathrm{C}$ in synthetic air. With a nominal Co-to-Ni ratio of approximately 1.4, this novel alloy was developed to achieve high $\gamma^{\prime}$-solvus temperatures and therefore as potential candidate for disc material that is needed to further increase service temperatures in classical high-temperature applications such as gas turbines. A special focus lies therefore on compositional alterations in regions adjacent to the internal oxidation front (IOF). Furthermore, an advanced alloy with reversed $\mathrm{Co} / \mathrm{Ni}$ ratio, ERBOCo-1X, is addressed to unambiguously identify the role of the base element in multinary $\mathrm{Co} /$ Ni-base superalloys. Selected experiments were also conducted with the commercial Ni-base superalloy CMSX-4 to elucidate, if the oxidation properties of the ERBOCo alloys reach comparable levels of an established Ni-base disc material.

\section{EXPERIMENTAL PROCEDURES}

\section{A. Sample Materials}

Oxidation experiments of three single-crystalline $\gamma /$ $\gamma^{\prime}$-hardened superalloys were conducted. The multinary Co-base alloys ERBOCo- $1^{[1]}$ and ERBOCo- $1 \mathrm{X}^{[24]}$ were cast as single crystals (SX) with an intended $<001>$ orientation along the rod-axis (diameter $12 \mathrm{~mm}$ ) via Bridgeman investment casting by the Institute of Metals Science and Technology (WTM, University of Erlangen-Nürnberg (FAU), Germany). The compositions were determined by inductively coupled plasma optical emission spectrometry (ICP-OES) in the as-cast state (Institut für Materialprüfung Glörfeld $\mathrm{GmbH}$, Germany). Table I provides the nominal and the measured values and illustrates a good concurrence of both. Samples after different heat treatments were tested to investigate the influence of solidification-induced elemental segregations (dendrites) on oxidation.

The As-Cast state (AC) was studied as a reference, as this material shows the most pronounced differences between Dendritic (D) and InterDendritic (ID) regions. To adjust intermediate homogeneity, a Heat Treatment of Short duration (HTS) was conducted as introduced by Volz et al. ${ }^{[1]}$ HTS is comprised of a solution annealing step for a duration of 8 hours at $1280{ }^{\circ} \mathrm{C}$ $\left(\gamma^{\prime}\right.$-solvus temperatures of $1145^{\circ} \mathrm{C}$ and $1195^{\circ} \mathrm{C}$ are reported for ERBOCo-1 and ERBOCo-1X, respectively ${ }^{[24]}$ ) followed by an aging treatment at lower temperatures to obtain $\gamma / \gamma^{\prime}$-microstructure. A Longterm Heat Treatment (HTL) that consisted of HTS procedure and subsequent exposure for 100 hours at $1280{ }^{\circ} \mathrm{C}$ followed by the two-step HTS aging facilitated an even higher degree of homogeneity. The details on both heat treatments are provided in the following:

- HTS: $8 \mathrm{~h}$ at $1280{ }^{\circ} \mathrm{C} \rightarrow 5 \mathrm{~h}$ at $1050{ }^{\circ} \mathrm{C} \rightarrow 16 \mathrm{~h}$ at $900{ }^{\circ} \mathrm{C}$

- HTL: HTS $\rightarrow 100$ h at $1280{ }^{\circ} \mathrm{C} \rightarrow 5$ h at $1050{ }^{\circ} \mathrm{C} \rightarrow$ $16 \mathrm{~h}$ at $900^{\circ} \mathrm{C}$

The heat treatment was performed by using a furnace from Nabertherm (model: RHTC 80-450) that was operated with heating and cooling rates of $5 \mathrm{~K} / \mathrm{min}$ at a pressure below $5 \times 10^{-5}$ mbar.

The commercial superalloy CMSX-4 was provided by Doncasters Precision Casting (ingot dimensions: $100 \times 20 \times 140 \mathrm{~mm}^{3}$ ). The nominal composition was verified by standardless SEM-EDX (Table II). Comparing the nominal and the measured composition, it is 
Table II. Nominal ${ }^{[27,28]}$ and Actual Elemental Composition of CMSX-4 in At. Pct, Determined by Standardless SEM-EDX

\begin{tabular}{llllllllllll}
\hline & $\mathrm{Co}$ & $\mathrm{Ni}$ & $\mathrm{Al}$ & $\mathrm{Cr}$ & $\mathrm{W}$ & $\mathrm{Ti}$ & $\mathrm{Ta}$ & $\mathrm{Hf}$ & $\mathrm{Mo}$ & $\mathrm{Re}$ & $\mathrm{Co} / \mathrm{Ni}$ \\
\hline Nominal & 10 & 62.9 & 12.6 & 7.5 & 2.1 & 1.3 & 2.2 & 0.03 & 0.4 & 1.0 & 0.159 \\
Measured & 10.14 & 60.25 & 14.35 & 7.19 & 4.25 & 1.12 & 1.33 & & 0.37 & 0.99 & 0.168 \\
\hline
\end{tabular}

The Hf-content is not provided, as it is below the limit for reasonable EDX measurements.

noteworthy that the Ta content is slightly underestimated, whereas the $\mathrm{W}$ content seems too high. Most probably, the overlap of $\mathrm{W}$ and Ta EDX spectra caused these inaccuracies. ${ }^{[25,26]}$ In contrast to the ERBOCo alloys, the commercial superalloy CMSX-4 was investigated in heat-treated state, only. The heat treatment is based on a stepwise solution annealing up to $1300{ }^{\circ} \mathrm{C}$ followed by aging at $1140{ }^{\circ} \mathrm{C}$ and $870^{\circ} \mathrm{C}$ for $4 \mathrm{~h}$ and $16 \mathrm{~h}$, respectively (see Reference ${ }^{[27]}$ ).

After heat treatment, samples with a thickness of 1 $\mathrm{mm}$ were cut from the SX rods. Subsequently, a hole (diameter of $2 \mathrm{~mm}$ ) was drilled in margin proximity (to suspend the samples during degreasing and oxidation). After grinding up to a grit size of $1200 \mathrm{SiC}$, polishing was conducted, using $9,3 \mu \mathrm{m}$, and finally $1 \mu \mathrm{m}$ diamond suspension. Before oxidation, the polished samples were degreased by ultrasonication in acetone and ethanol.

\section{B. Oxidation}

To assess the oxidation kinetics, continuous thermogravimetry was conducted in a SETSYS Evolution 1650 TGA from Setaram for durations of up to 100 hours in synthetic air (20 pet $\mathrm{O}_{2}, 80$ pet $\mathrm{N}_{2}$ from Linde) at $850{ }^{\circ} \mathrm{C}$ and $1050{ }^{\circ} \mathrm{C}$. The decision to $850^{\circ} \mathrm{C}$ as the lower exposure temperature was made to provide comparability to former studies. ${ }^{[9,10,12,20]}$ As the development of superalloys targets on increasing the maximum service temperature, for the application-oriented superalloys ERBOCo-1 and ERBOCo-1X experiments well beyond $850{ }^{\circ} \mathrm{C}$ were of particular interest, too. Since the $\gamma^{\prime}$-volume fraction significantly lowers beyond this temperature ${ }^{[1]}$ and again in order to provide comparability to available literature, ${ }^{[1,19,20]}$ $1050{ }^{\circ} \mathrm{C}$ were chosen to address the high-temperature regime. Heating and cooling rates of $5 \mathrm{~K} / \mathrm{min}$ were used for these experiments. Gas flow rates were set to $20 \mathrm{~mL} / \mathrm{min}$ what equals a laminar gas velocity of $7.86 \mathrm{~cm} / \mathrm{min}$. Taring of the balance was conducted prior to temperature ramp up, meaning that mass changes during heating were recorded. For the experiments of shorter durations (12 and 24 hours), a higher heating rate $(25 \mathrm{~K} / \mathrm{min})$ was used. Thereby, the differences in total exposure duration between samples heated up to $850{ }^{\circ} \mathrm{C}$ and those heated up to $1050{ }^{\circ} \mathrm{C}$ are kept low. The experiments of 500 hours duration were performed in a furnace without thermobalance, also using constant flow of synthetic air at identical heating and cooling rates $(5 \mathrm{~K} / \mathrm{min})$.

\section{Microscopic Characterization and Preparation of Cross Sections}

To clearly depict the two-phase microstructure, ion milling (75 deg incidence angle) was conducted prior to metallurgical characterization of the mechanically pre-polished alloys. Due to different sputtering rates between $\gamma$ - and $\gamma^{\prime}$-phase, a surface topography is generated which increases the contrast in subsequent microscopic investigation. For the latter, a scanning electron microscope (SEM) (Tescan LYRA3) equipped with a backscattered electron (BSE) detector was used.

Subsequent to oxidation, Ni plating was performed in order to prevent scale spallation during metallurgical preparation of cross sections. Therefore, firstly a thin electrically conductive Au layer was applied by sputtering. Afterwards, galvanostatic electroplating was performed using a $\mathrm{NiSO}_{4}$-based solution $\left(750 \mathrm{~mL} \mathrm{H}_{2} \mathrm{O}\right.$,

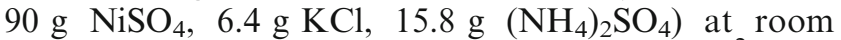
temperature and a current density of $15 \mathrm{~mA} / \mathrm{cm}^{2}$ for a duration of 30 minutes. After Ni plating, the samples were embedded in cold-polymerizing resin in upright position. Manual grinding with grit size of P1200 SiC was conducted until the center of the sample was approximately reached. Subsequently, the embedded samples were polished down to $3 \mu \mathrm{m}$ grit size, using diamond suspension. For further preparation, resin was removed by immersion in dichloromethane $\left(\mathrm{CH}_{2} \mathrm{Cl}_{2}\right)$ for approximately 5 hours. Afterwards, an ion-milling cut (IM4000 from Hitachi) was conducted across the mechanically pre-polished samples. This extensive metallographic preparation was necessary to reach micrographs at the desired quality from the brittle multilayered oxide scales. The SEM micrographs were taken by using a Tescan LYRA3 microscope. To elucidate the elemental distribution across the oxide scale and within adjacent alloy regions, elemental maps and linescans were taken by electron probe microanalysis (EPMA, JXA-8100 from JEOL) from the selected samples.

\section{RESULTS AND DISCUSSION}

\section{A. Influence of Homogenization Annealing on Microstructure and Elemental Segregations}

Figure 1 indicates microstructural differences between dendritic (marked with "D") and interdendritic regions (marked with "ID") for samples in the as-cast state (AC) and samples after short heat treatment (HTS). It is noteworthy that the size of the $\gamma^{\prime}$-precipitates within the dendritic regions is generally smaller compared to the interdendritic areas in both HTS and AC state (see e.g., Figures 1(e) and (g) vs. f and h). Besides the size, also the morphology of the hardening phase varies. In comparison to a rather cuboidal geometry in the case of ERBOCo-1-HTS (see Figures 1(e) and (f)), an almost rounded morphology, especially within the dendrite cores, can be recognized in case of ERBOCo-1X-HTS 
ERBOCo1
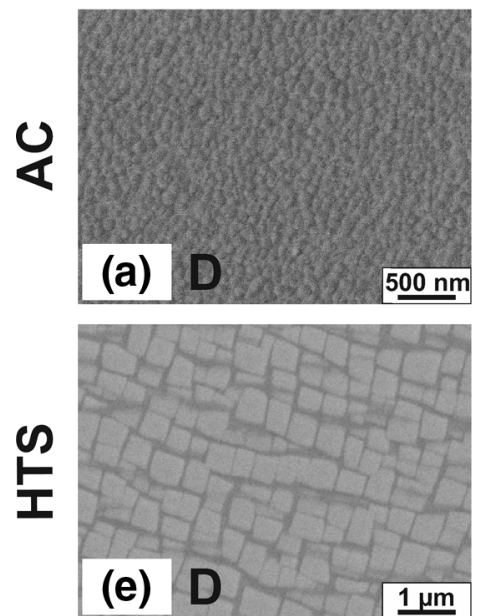
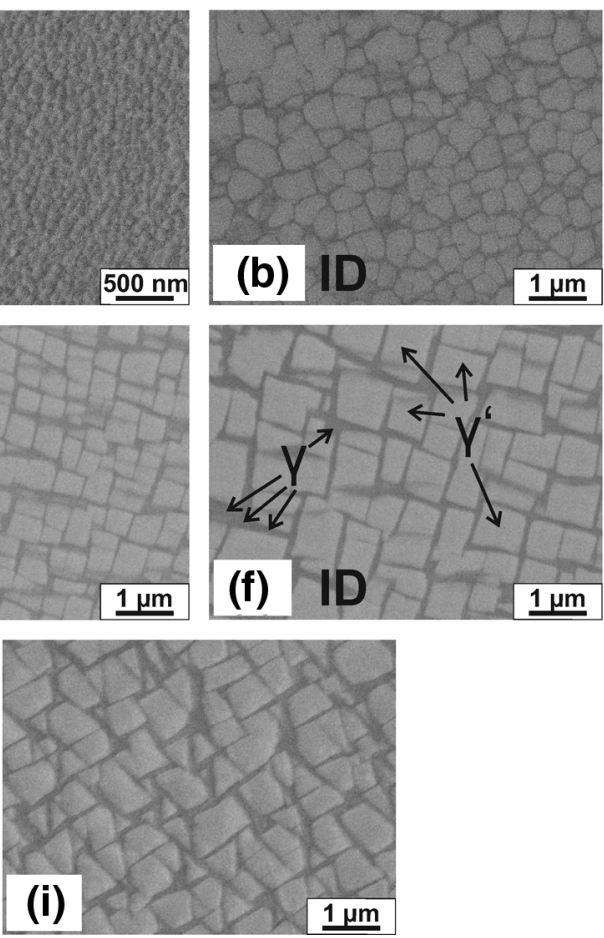

ERBOCo1X
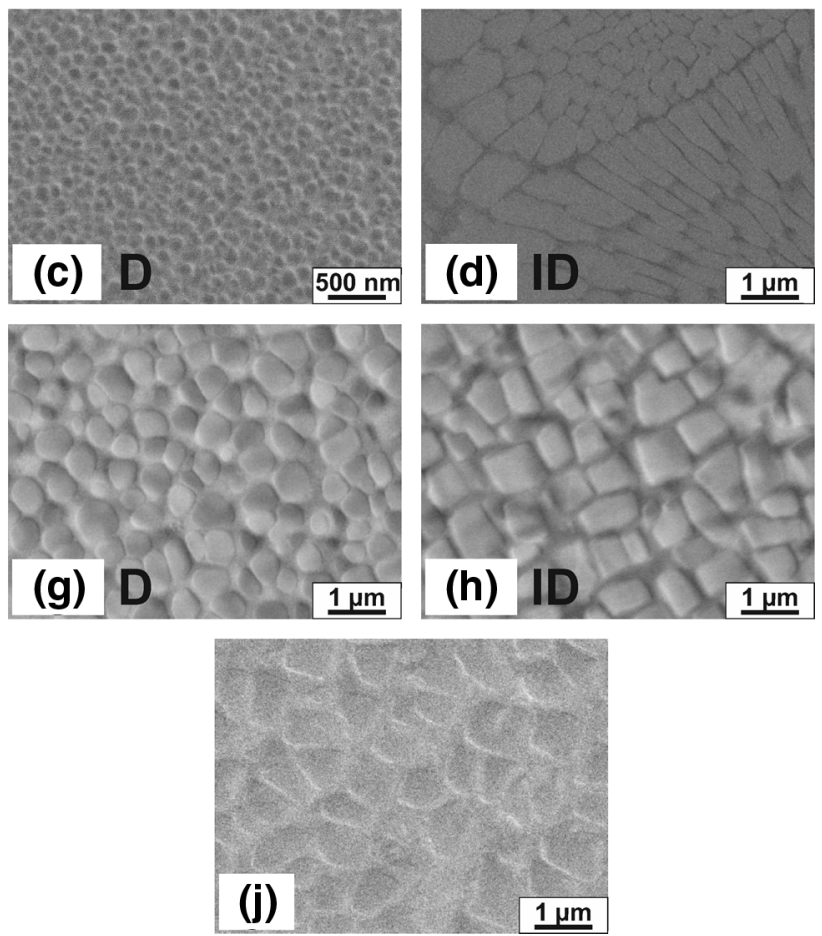

Fig. 1-BSE micrographs of investigated model alloys. For AC state $((a)$ and $(b)$ for ERBOCo-1-AC; $(c)$ and $(d)$ for ERBOCo-1X-AC)) and HTS state $((e)$ and $(f)$ for ERBOCo-1-HTS; $(g)$ and $(h)$ for ERBOCo-1X-AC), both dendritic regions (indicated by D) and interdendritic regions (indicated by ID) are depicted. For HTL state ( $(i)$ for ERBOCo-1-HTL; $(j)$ for ERBOCo-1X-HTL) one representative micrograph was chosen. Both phases, $\gamma$ (channel) and $\gamma^{\prime}$ (precipitates), are exemplarily marked in $\mathrm{f}$.

(Figures $1(\mathrm{~g})$ and $(\mathrm{h})$ ). In $\mathrm{AC}$ state the size of the hardening phase within the dendritic regions is close to the resolution limit of the SEM. Just as for the HTS state, also in AC condition a rounded morphology within dendritic regions is revealed (Figures 1(a) and (c)). Comparing the microstructure in HTS state and after long heat treatment (HTL), it is apparent that the $\gamma^{\prime}$-size after prolonged homogenization levels between the range depicted for the short heat treatment (see e.g., Figure 1(i) vs. (e) and (f) for ERBOCo-1).

Elemental distribution maps (EPMA) were taken in AC, HTS, and HTL state for ERBOCo-1. In AC state for the interdendritic regions, above-average contents of $\mathrm{Ni}, \mathrm{Al}, \mathrm{Ti}, \mathrm{Ta}, \mathrm{Si}$, and $\mathrm{Hf}$ are clearly seen, whereas $\mathrm{Co}$, $\mathrm{Cr}$, and $\mathrm{W}$ are strongly enriched in the dendrite cores (the EPMA maps for AC state are provided within "Appendix", see Figure A1).

It is noteworthy that the short heat treatment (HTS) was insufficient to gain equal elemental distributions, as still a considerable degree of segregation as well as some precipitates of a phase other than $\gamma$ and $\gamma^{\prime}$ are detectable (Figure 2). Within the dendritic regions $\mathrm{Co}$ and $\mathrm{Cr}$, but especially $\mathrm{W}$ are still on above-average concentrations, not only in the case of both ERBOCo alloys, but also in the case of CMSX-4 (see Reference [20]).

To emphasize the success of the long heat treatment (HTL) with respect to elemental redistribution, Figure 3 depicts the $\mathrm{W}$ distribution not only in HTL condition (c and d), but also for AC (a) and HTS conditions (b). W was selected as this element is well known for having a low elemental diffusivity. ${ }^{[29-31]}$ It is obvious that the severity of segregations clearly decreased with prolonging the homogenization period. Thus, in HTL state very little residual segregations remained present. According to Zenk et al., in the case of ERBOCo-1X, a slightly higher degree of segregation prevails in AC and HTS conditions. ${ }^{[24]}$ In HTL state, however, also in the case of ERBOCo-1X, a significant homogenization was achieved.

Overall, these results show that segregation-induced compositional differences affect the local microstructure of the alloys in AC and HTS state. Both might affect the prevailing oxidation mechanism, in addition to the nominal chemical composition of the alloys.

\section{B. High-Temperature Oxidation at $850^{\circ} \mathrm{C}$}

Figure 4 shows the oxidation behavior of the three investigated alloys during an exposure to synthetic air for 100 hours at $850^{\circ} \mathrm{C}$; the ERBOCo alloys were studied in the HTS state (short heat treatment). After an initial period of about 40 hours, both ERBOCo alloys demonstrate a lower mass gain than the commercial Ni-base superalloy.

Although the Co-base alloy (ERBOCo-1) slightly outmatches its Ni-base derivate (ERBOCo-1X) in this respect, comparable oxidation resistances can be 


\section{$100 \mu \mathrm{m}$}
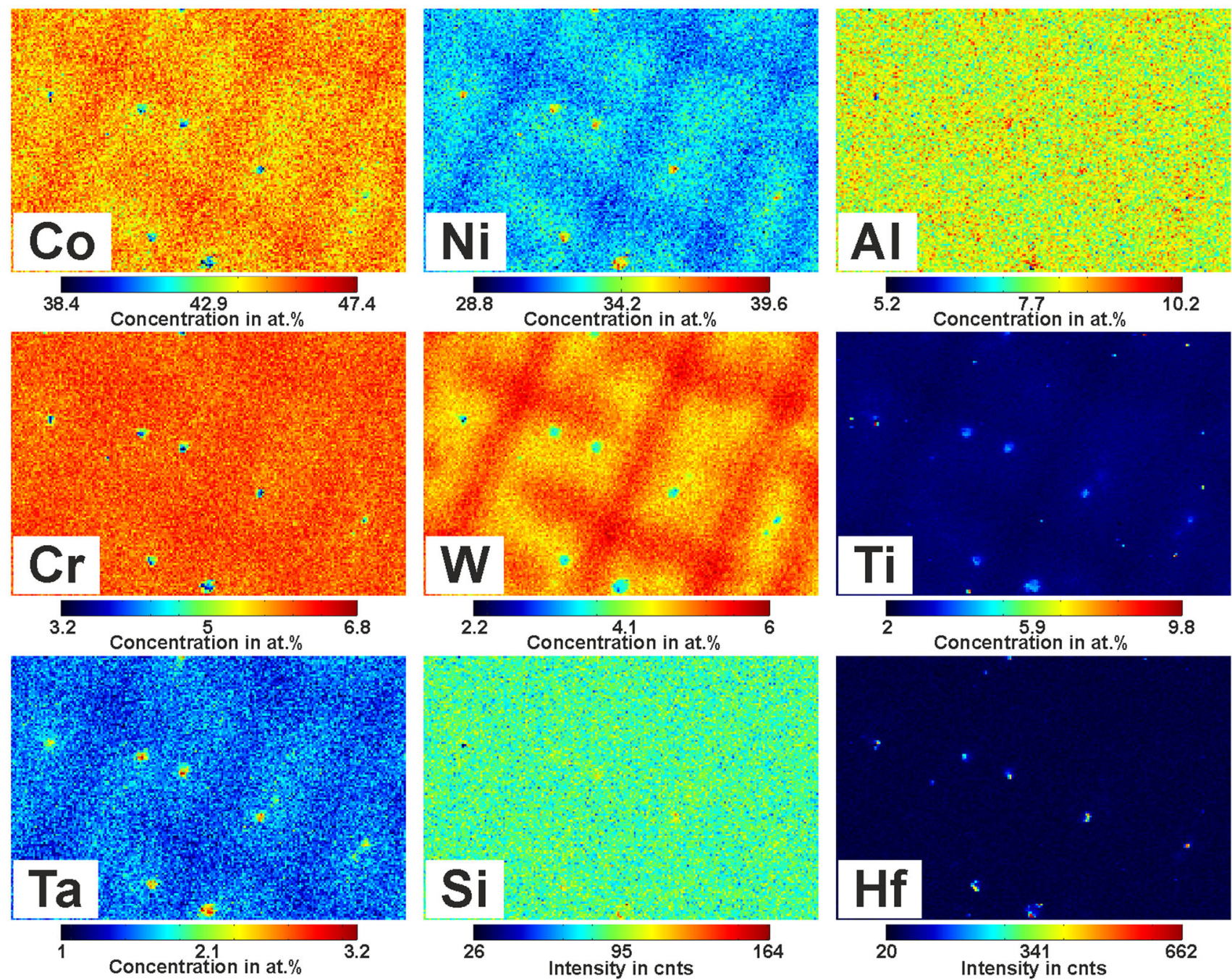

Fig. 2-BSE micrograph and corresponding elemental distribution maps determined by EPMA for ERBOCo-1-HTS. Color coding shows elemental concentrations in at. pct for $\mathrm{Co}, \mathrm{Ni}, \mathrm{Al}, \mathrm{Cr}, \mathrm{W}, \mathrm{Ti}$, and $\mathrm{Ta}$ (sum of the latter equaling 100 at. pct). As the software did not allow a quantification in case of $\mathrm{Si}$ (nominal concentration of 0.4 at. pct) and $\mathrm{Hf}(0.1$ at. pct), solely qualitative plots representing the intensity are depicted, instead.

concluded, since the differences are marginal and lie in the typical magnitude of experimental uncertainty of the used TG analyzer.

The mass-gain curves of both alloys, ERBOCo-1 and ERBOCo-1X, do not indicate apparent changes of the reaction kinetics. In contrast, the thermogravimetric data of CMSX-4 are prone to sudden alterations in slope throughout the entire experiment. The results of
CMSX-4 are provided at this point solely for the sake of clarity and will be elucidated in more detail later in the manuscript (Section III-D).

To obtain details on the scale structure of the ERBOCo alloys, scanning electron micrographs of cross sections after exposure for 12 and 100 hours at $850{ }^{\circ} \mathrm{C}$ are provided in Figure 5. The SEM-based analysis indicates the development of rather inhomogeneous oxide scales. The dendritic sample regions reveal a 

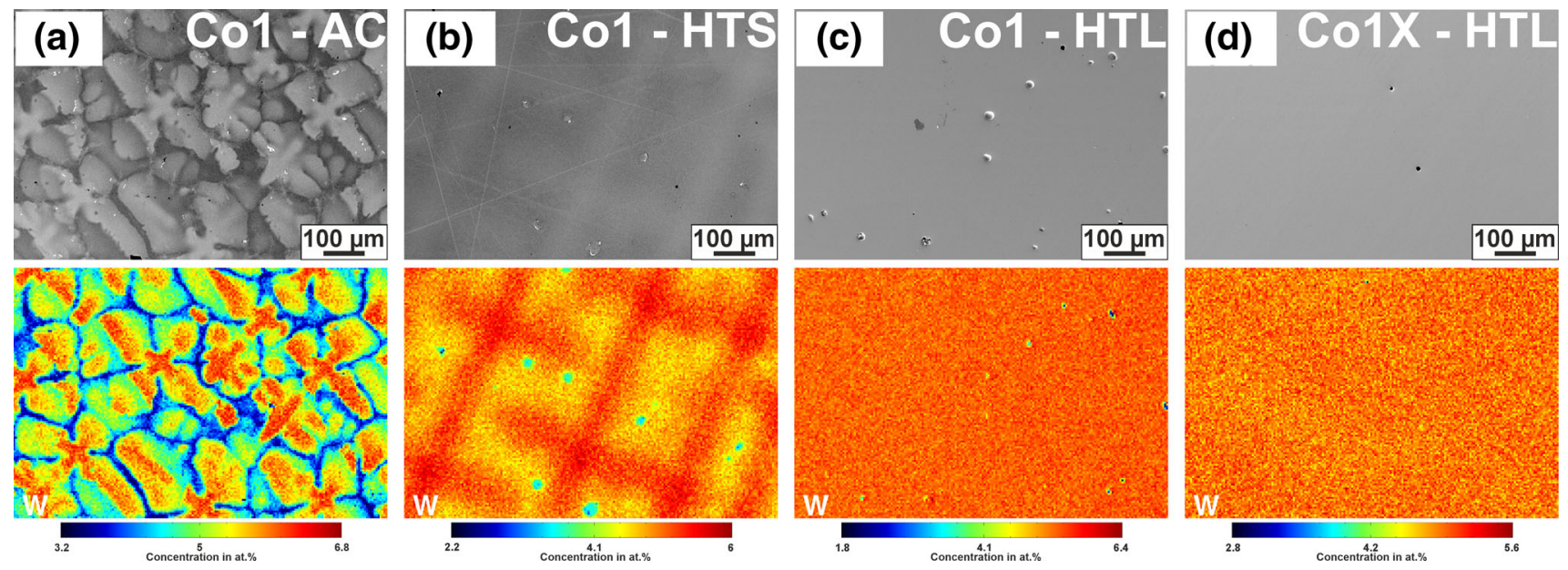

Fig. 3-BSE micrographs and corresponding W distribution maps determined by EPMA for ERBOCo-1 in (a) AC, (b) HTS, and (c) HTL state as well as ERBOCo-1X in HTL state $(d)$.

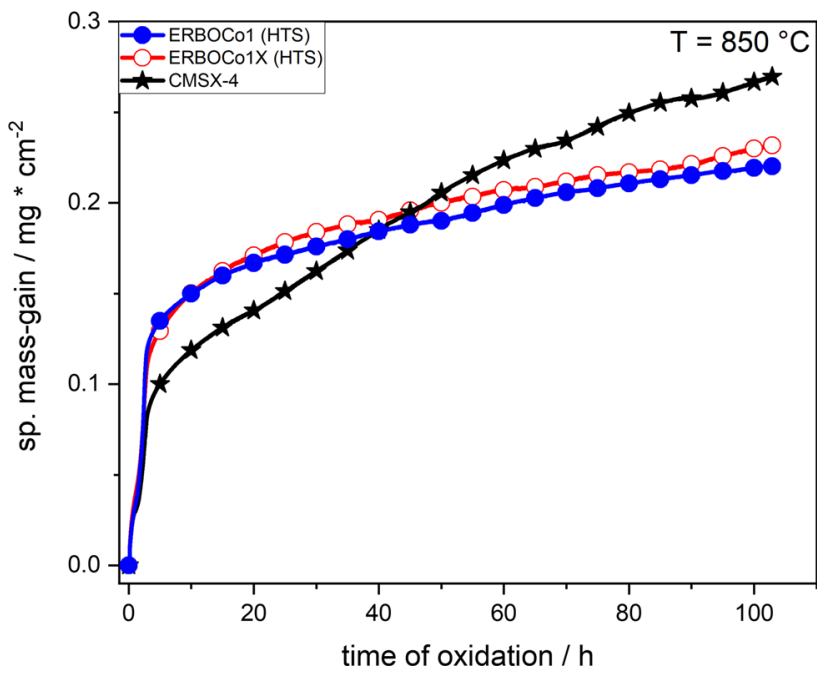

Fig. 4 - Continuous specific mass-gain curves, recorded during isothermal oxidation for $100 \mathrm{~h}$ at $850^{\circ} \mathrm{C}$ of ERBOCo-1-HTS and ERBOCo-1X-HTS as well as CMSX-4.

higher tendency for the growth of thick scales than interdendritic sections. It must be clearly noted for the $850{ }^{\circ} \mathrm{C}$ experiments that the spatial expansion of these local thickness variations is smaller than the length scale on which the dendritic segregations prevail for both alloys. I.e., within the dendritic regions (respectively interdendritic) also scale sections of somewhat lower (respectively higher) thicknesses could be found.

For an exposure time of 12 hours, a similar scale structure is revealed for dendritic and interdendritic regions of both alloys (see Figures 5(a), (c), (e), and (g)). Hence, for all spots both an external oxide scale as well as a subjacent internal oxidation zone (IOZ) can be found (both exemplarily labeled within Figure 5(a)). The external scale can be expected to consist out of a solid solution of $\mathrm{Co}$ and $\mathrm{Ni}$ oxides, due to available literature on similar systems ${ }^{[12,18,32,33]}$ and due to the EPMA results on hand for $1050{ }^{\circ} \mathrm{C}$ (see e.g., Figures 11(a) and 12). Within the IOZ, dark oxide particles are embedded that are exemplarily labeled in Figures 5(b) and (d). Since the BSE contrast is linked to the average atomic mass of a phase, and since alumina is the lightest oxide for both alloys that is expected to grow, these spots can consequently be identified as alumina (also see EPMA results for $1050{ }^{\circ} \mathrm{C}$ and literature ${ }^{[10,34,35]}$ ). It is noteworthy that the size of the distinct alumina precipitates is highly comparable after 12 hours of oxidation, regardless of the type of alloy or of residual segregations.

Increasing the exposure duration to 100 hours leads to the formation of apparent differences between dendritic and interdendritic regions with respect to alumina growth (compare Figure 5(b) with d for ERBOCo-1 and $\mathrm{f}$ with $\mathrm{h}$ for ERBOCo-1X).

Clearly, a coarsening of the alumina precipitates is detectable at the dendritic positions (comparing especially Figures 5(e) and (f)). The precipitates, however, still do not exhibit lateral coalescence that would be an indication for the transition to protective scale growth ${ }^{[36]}$ Instead, they penetrate deeply into the alloy.

Within the interdendritic regions, for both alloys but especially for ERBOCo-1, an increasing growth tendency of alumina right below the outer oxide layer can be recognized (compare Figures 5(c) with (d)). In contrast to the dendritic regions, after 100 hours a certain degree of lateral connectivity of alumina is obvious for ERBOCo-1 (Figure 5(d)). This peculiarity of ERBOCo-1 at $850{ }^{\circ} \mathrm{C}$ matches well with the lower scale thickness $(0.74$ vs. $1.24 \mu \mathrm{m}$, see Figures $5(\mathrm{~d})$ and (h)) and with its promising TGA results provided in Figure 4. However, comparing Figure 5(a) with (c), it must be clearly stated that highly accelerated reaction rates already after 12 hours of exposure, leading to an average oxide thickness of $1.63 \mu \mathrm{m}$, could be detected for ERBOCo-1, too.

Below the IOZ, a $\gamma^{\prime}$-depleted zone is allocated which is exemplarily marked in Figure 5(a) by means of a white line. This zone is generally thicker at the dendritic regions. In the case of ERBOCo- $1 \mathrm{X}$, due to the low contrast of the micrographs, the latter is only recognizable after 100 hours of exposure. 
ERBOCo1

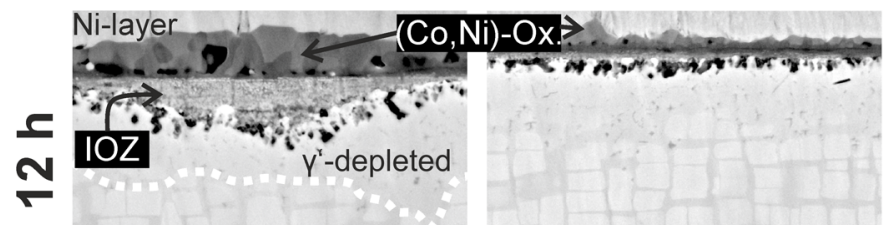

(a) $\quad \mathrm{d}_{0 x}=1.63 \mu \mathrm{m}$

(a) D $1 \mu \mathrm{m}$

(c) ID

$\mathrm{d}_{\mathrm{ox}}=0.62 \mu \mathrm{m}$

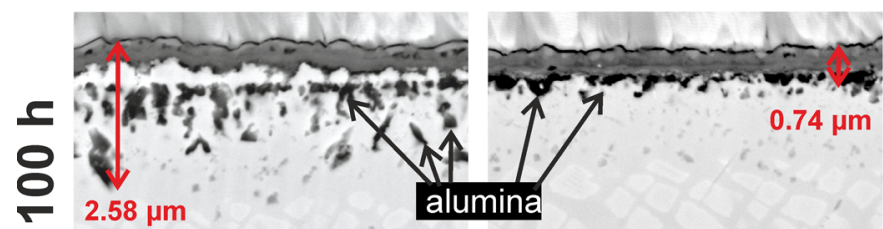

(b)
$1 \mu \mathrm{m}$
ERBOCo1X

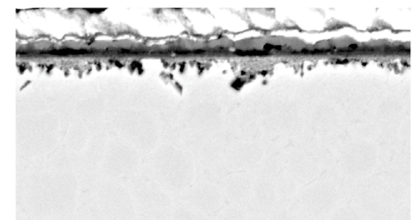

(e)

$d_{o x}=0.61 \mu \mathrm{m}$

$1 \mu \mathrm{m}$

(g) ID

$\mathrm{d}_{\mathrm{ox}}=0.59 \mu \mathrm{m}$

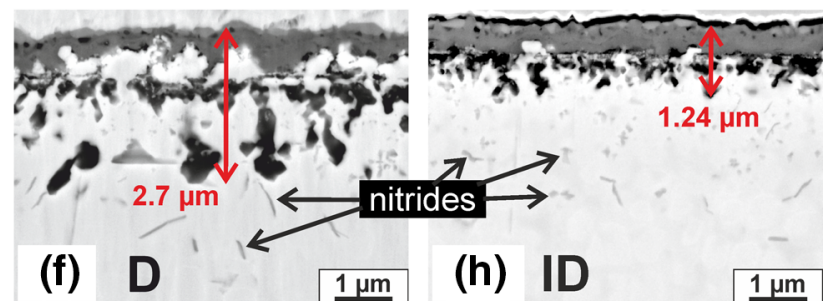

Fig. 5-BSE micrographs of cross sections of ERBOCo-1-HTS (left: $a$ to $d$ ) and ERBOCo-1X-HTS (right: $e$ to $h$ ) after $12 \mathrm{~h}$ (upper row) and $100 \mathrm{~h}$ (lower row) of exposure at $850^{\circ} \mathrm{C}$. Micrographs a, b, e, and f depict thick scale spots grown at dendritic regions. Thin scale spots of interdendritic regions are provided in $\mathrm{c}, \mathrm{d}, \mathrm{g}$, and $\mathrm{h}$. The average thickness of the oxide scale is provided for a, $\mathrm{c}$, e, and g. The red arrows (b, $\mathrm{d}$, $\mathrm{f}$, and $\mathrm{h}$ ) indicate the max. thicknesses on hand at the depicted spots.

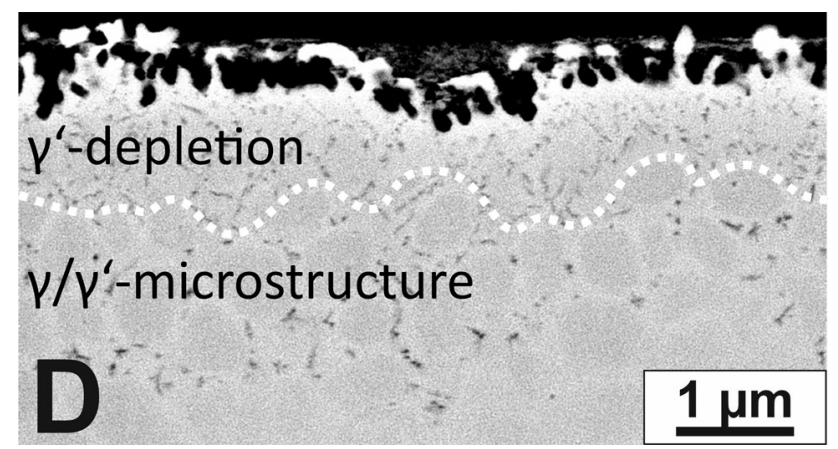

Fig. 6-BSE micrograph of a cross section of ERBOCo-1X-HTS, oxidized for $24 \mathrm{~h}$ at $850^{\circ} \mathrm{C}$. The contrast of the micrograph was artificially increased to allow a better recognition of the internal phases. The white line represents the border below which $\gamma$ and $\gamma^{\prime}$-phase can be found.

Furthermore, below the IOZ and especially after 100 hours of exposure (exemplarily labeled in Figures 5(f) and (h)), the growth of further dark-appearing phases can be identified.

Considering EPMA results on hand for $1050{ }^{\circ} \mathrm{C}$ (see e.g., Figures 11(a) and 12), these precipitates can be expected to be nitrides. The development of nitrides in Co-base alloys was repeatedly demonstrated in literature. ${ }^{[37-41]}$ It is worth mentioning that the latter, also formed below the $\gamma^{\prime}$-depleted zone, where they are strictly aligned towards the channel phase (Figure 5(d)). To demonstrate their preferential growth in the matrix, a detailed micrograph of the Ni-rich sample after 24 hours of oxidation at $850{ }^{\circ} \mathrm{C}$ is shown in Figure 6 .

Overall, the results for $850{ }^{\circ} \mathrm{C}$ indicate that both ERBOCo alloys are not capable of growing continuous protective alumina scales during an exposure for up to 100 hours. Below the outer oxide layer an IOZ of distinct alumina precipitates prevails at least locally. The latter is not effective in retarding the inward penetration of reactive species (oxygen or nitrogen).

\section{High-Temperature Oxidation at $1050^{\circ} \mathrm{C}$}

At $1050{ }^{\circ} \mathrm{C}$, samples were investigated by means of TGA in as-cast state (AC), after short heat treatment (HTS), and after long heat treatment (HTL). In contrast to the TGA results at lower temperature, a definite order regarding the alloy specific oxidation kinetics prevails (see Figure 7). This means that at $1050{ }^{\circ} \mathrm{C}$ all samples of the Co-base alloy exhibit less resistance against oxidation than their Ni-base counterpart. The commercial CMSX-4 alloy shows by far the lowest mass gain throughout the entire duration of exposure. The massive oxide scales that developed for both ERBOCo alloys have a high probability to spall during cooling. For exposure times up to 100 hours, the generated stresses inside the oxide scale might have caused the formation of microcracks, since spallation of scale regions occurred to a minor extent during the cooling. Since these processes of stress relieve appeared randomly and after oxidation, they are not considered in further detail.

For both ERBOCo alloys by far the largest mass gains were recorded in the AC condition. The latter were followed by the samples in HTS condition, whereas the slowest reaction kinetics were detected for specimens that exhibit the highest homogeneity (HTL). Therefore, especially with respect to the results from Section III-A, a detrimental impact of the residual solidification-induced elemental segregations on the oxidation resistance for both ERBOCo alloys can be concluded.

Figure 8 illustrates the influence of the segregation-induced local alteration of the alloy composition on the oxide growth by comparing top-view micrographs of oxidized samples. 
According to Figures 8(a) and (b) (AC state), the typical dendrite shape is clearly represented in the oxide topography on both alloys. Since the top-view images were taken in SE mode (in which ridges are depicted brightly), one can conclude that the dendritic regions excel the interdendritic regions in terms of oxide thickness. The latter is clearly more pronounced in the case of the Co-rich alloy (Figure 8(a)).

In HTS condition, much less distinct oxide structures (on the length scale of dendrites) can be detected after 100 hours of exposure (Figures 8(c) and 5(d)), indicating more evenly distributed oxide growth rates along the surface for both alloys. After 500 hours of oxidation, however, the stress level inside the oxide scale during

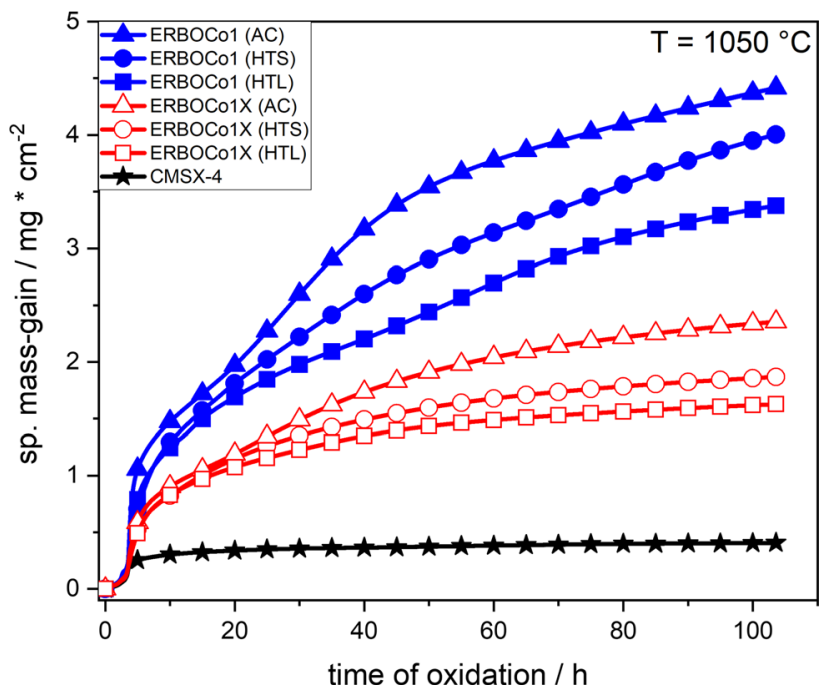

Fig. 7-Continuous specific mass-gain curves, recorded during isothermal oxidation for $100 \mathrm{~h}$ at $1050{ }^{\circ} \mathrm{C}$ of ERBOCo-1 (3 blue curves: AC, HTS, and HTL conditions) and ERBOCo-1X (3 red curves: AC, HTS, and HTL conditions) as well as CMSX-4 (black curve). cooling surpassed a critical level that led to complete separation of the upper scale section from the substrate. Interestingly, the dendrite structure can be recognized in HTS samples (Figures 8(g) and (h)) after spallation. The dendrite cores demonstrate an apparently porous IOZ at the fracture surface. Within the interdendritic regions, scattered alumina particles but mainly bare metal are allocated. Therefore, also in the HTS state a strong impact of residual segregations on the oxide formation at $1050{ }^{\circ} \mathrm{C}$ can be concluded. In the case of extended homogenization (HTL), clearly, the smoothest surfaces are depicted (compare Figure 8(c) with (e) and (d) with (f)). Overall, Figure 8 obviously indicates that truly dendritic segregations affect the local oxidation resistance. Apparent differences regarding the local oxidation rates could be decreased by heat treatment prior to oxidation. The elemental redistribution through HTS was identified to be insufficient to assure homogeneous oxide growth.

To characterize the impact of homogenization on oxide thickness quantitatively, a more detailed investigation of the cross sections was conducted. Extreme values were evaluated for the analysis. Dimensions of the thickest (Figure 9(a)) and the thinnest (Figure 9(b)) scale spots of each composition are plotted in a separate graph. The oxide thickness was defined as the distance between the outer oxide surface and the subjacent oxide/ metal interface. Details on the thickness measurements (Figure A2) as well as representative cross sections for AC and HTL state (Figure A3) are provided within the "Appendix". In the case of the cross sections of AC and HTS samples, the W enrichment within the dendrite cores allowed to identify dendritic and interdendritic regions by means of BSE contrast. For AC and HTS samples, dendritic regions (respectively interdendritic) clearly coincided well with regions of thick (respectively thin) oxide scales. For HTL samples, however, BSE contrast was insufficient to subdivide between dendritic and interdendritic regions.
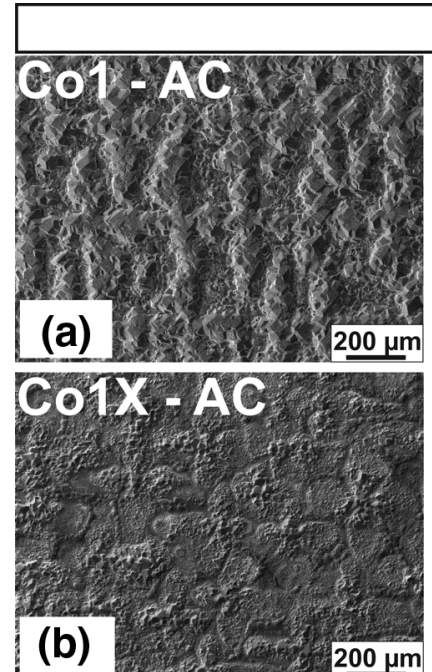
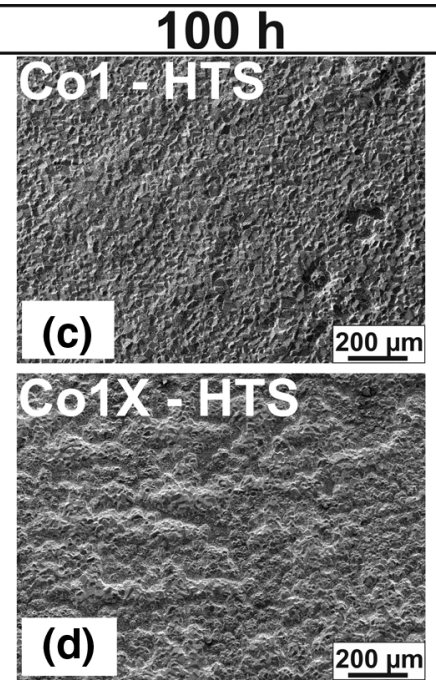
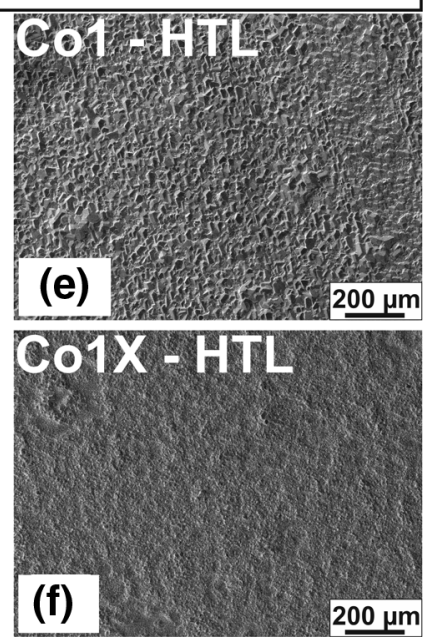
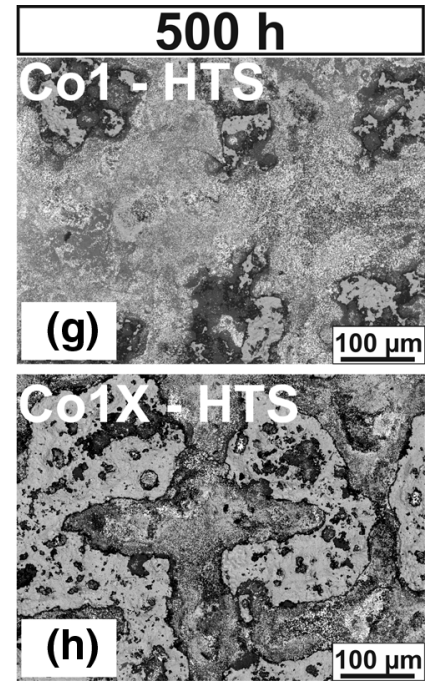

Fig. 8-Top-view micrographs taken in SE mode for ERBOCo-1 (upper row) and ERBOCo-1X (lower row) after oxidation at $1050{ }^{\circ} \mathrm{C}$ for $100 \mathrm{~h}$ $(a, b, c, d$, and $f)$ and $500 \mathrm{~h}(g$ and $h)$. The samples in a and b refer to AC condition, the samples in $\mathrm{c}, \mathrm{d}$, g, h refer to HTS condition, and (e) and $\mathrm{f}$ to HTL condition. 


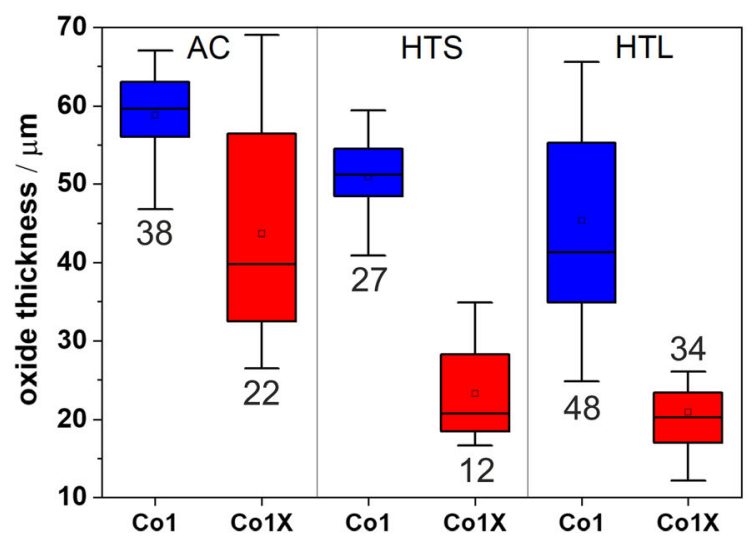

(a)

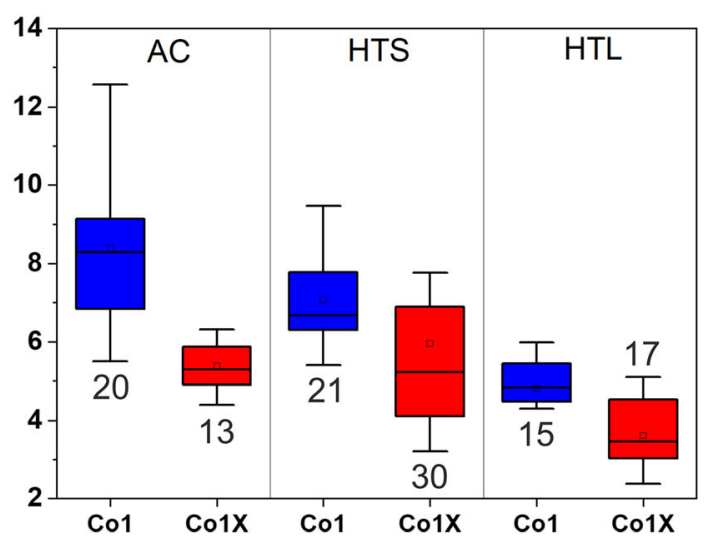

(b)

Fig. 9-Box-plot for extreme values of total scale thickness, with $(a)$ representing the thickest and $(b)$ the thinnest spots. The number of measured values is provided for each graph.

According to Figure 9, it is recognizable for both alloys that the scale thicknesses can be decreased with enhancing the homogeneity of the samples. This trend is much stronger reflected within the thick spots (Figure 9(a)) than it is for the thin ones (Figure 9(b)). Significantly thinner oxide scales after annealing indicate that the homogenization is not accompanied by a deterioration of the oxidation resistance of the interdendritic regions. This finding is remarkable, since the dendrite core composition was identified to be especially prone to oxidation (see Figures 8(a) and (b)). In other words, even though larger regions of the sample reveal a composition closer to the less-resistant dendritic regions through HTS and especially HTL, the oxidation behavior improves.

Generally, lower values of the oxide thickness are found for the Ni-base alloy and this is especially pronounced in case of the thick spots. However, for both the Ni-base and the Co-base system, pronounced differences in oxide scale thickness at different surface locations remain even in HTL condition. Overall, these results together with the TG analysis indicate that the overall mass gain is considerably determined by the reaction rates prevailing at the dendritic regions (and especially in case of ERBOCo-1).

It is assumed that especially the refractory metals (W and Ta) might be causative as the latter strongly segregate during solidification ${ }^{[42]}$ and as they are known to affect the oxidation resistance. ${ }^{[43]} \mathrm{W}$ enriches within the dendrite cores and is well known for decelerating diffusion of solutes like $\mathrm{Al}$ and $\mathrm{Cr} .^{[44-49]}$ According to Wagner ${ }^{[50]}$, the latter may impede protective scale formation, leading to the growth of thick scale sections along dendritic regions. Ta is-similar to $\mathrm{W}$-reported to decrease solute diffusion, however, enriches within interdendritic regions. ${ }^{[49,51]}$ Due to its high oxygen affinity for $\mathrm{Ta}$, a more ambiguous role on protective scale formation is reported, as it may also act as an oxygen getter and by that beneficially affect the formation of protective scales. ${ }^{[43,52,53]}$ This might contribute to the formation of a thin scale especially in interdendritic regions. Therefore, a lower concentration of $\mathrm{W}$ within dendritic regions and a simultaneously increased $\mathrm{Ta}$ level might together account for the beneficial impact of homogenization annealing.

Even though we consider this diffusion-based model as operative, it needs to be stated that $\mathrm{W}$ and $\mathrm{Ta}$ are also reported to increase the activity of $\mathrm{Al}$ and $\mathrm{Cr}^{[49]}$ and it is only an assumption that the impact on the latter is balanced due to divergent segregation behaviors of $\mathrm{Ta}$ and $\mathrm{W}$. Overall, the present study cannot unambiguously answer this mechanistic question.

To evaluate in detail, how oxide formation differs between dendritic and interdendritic regions, cross-sectional micrographs for 12,100 , and 500 hours of exposure are provided in Figure 10 for samples in HTS state.

Comparison of Figure 10(a) with (b) and Figure 10(c) with $(\mathrm{d})$ indicates that the dendritic composition of both alloys in HTS state is more susceptible to oxidation already during the early stages of scale growth. Whereas in case of top-view images, the latter remained concealed for an exposure duration of 100 hours (Figures 8(c) and (d)), it is clearly depicted within the respective cross sections (see Figures 10(a), through (d)). As described for $850{ }^{\circ} \mathrm{C}$ (Figure 5(a)), in particular the dendritic composition in case of ERBOCo- 1 remains prone to fast oxidative material degradation (see e.g., Figure 10(a)). Within the interdendritic regions, much thinner oxide scales grew for both alloys. It is noteworthy that in contrast to $850{ }^{\circ} \mathrm{C}$, within the high-temperature regime both the extent of thick and thin scale sections expand at dimensions of dendritic segregations (several tens of micrometers).

As already described before, an exposure duration of 500 hours resulted in spallation of the entire external oxide layer (Figures 8(g) and (h)). Figures 10(i) and (j) reveal that the internal oxidation zone (beneath the fracture surface) penetrates considerably deeper within the dendritic regions of both alloys. Even after 500 hours of oxidation, no continuous alumina layer can be found. Therefore, the massive formation of nitrides within the dendritic regions can be explained. The latter are exemplarily labeled in Figure 10(i) but can also be 
ERBOCo1

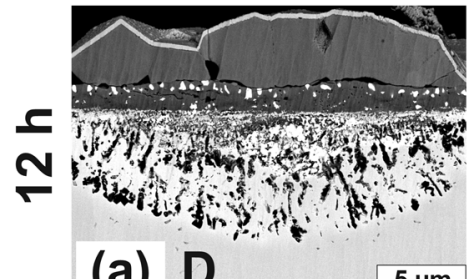

(a) D
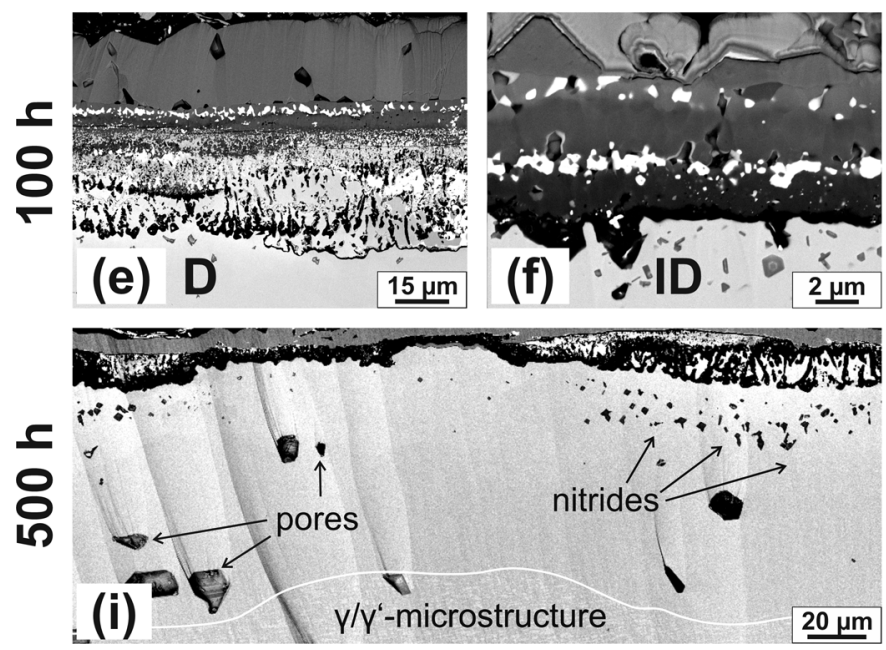
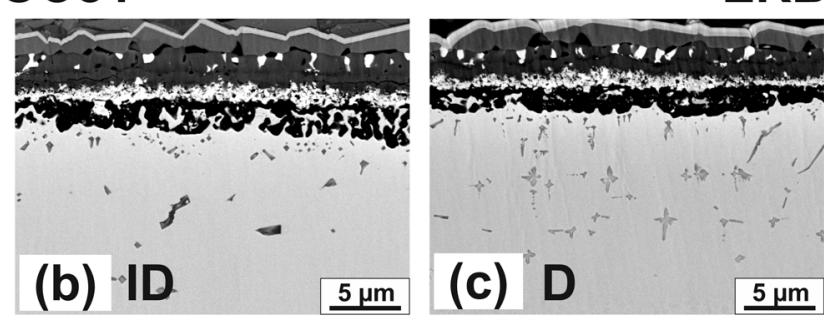

ERBOCo1X
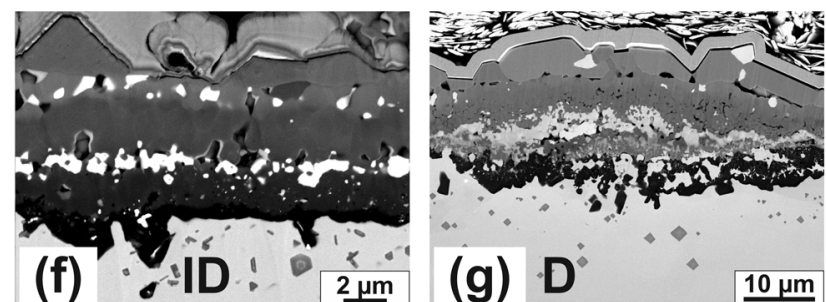
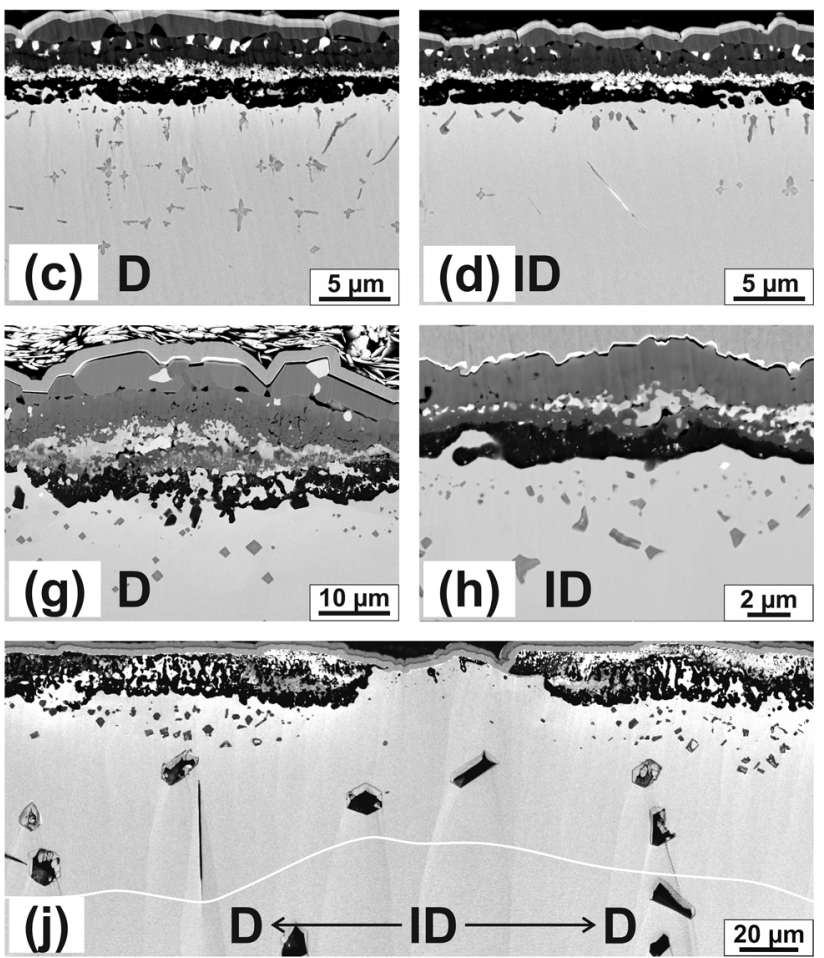

Fig. 10-BSE micrographs of cross sections of ERBOCo-1-HTS (left: $a, b, e, f$, and $i$ ) and ERBOCo-1X-HTS (right: $c, d, g, h$, and $j$ ) after 12 h (upper row), $100 \mathrm{~h}$ (central row), and $500 \mathrm{~h}$ (lower row) of exposure at $1050{ }^{\circ} \mathrm{C}$. Micrographs a, e, c, and g depict representative scale spots at dendritic regions, whereas for interdendritic regions the latter are provided in $\mathrm{b}, \mathrm{f}, \mathrm{d}$, and $\mathrm{h}$.

found for the Ni-base alloy and shorter exposure times. Furthermore, it is noteworthy that prolonging the exposure duration from 100 to 500 hours effectuated the growth of large pores within the substrate. In contrast to ERBOCo-1X, in the case of ERBOCo-1, the occurrence of these pores is only apparent in the $\gamma^{\prime}$-depleted zone that is indicated by means of the white lines in Figures 10(i) and (j). For both dendritic and interdendritic regions, the width of the $\gamma^{\prime}$-free zone is larger in the case of the Co-base alloy. This indicates that the width of the phase field in which the hardening phase is stable is strongly influenced by the Co contents. To characterize the elemental distribution within the scales and in the oxidation-affected region below the IOF, cross sections after 100 hours of exposure were additionally analyzed by means of EPMA (see Figure 11).

Since limited oxidation resistance of Co-base alloys remains a major drawback for potential applications, the following discussion considers mainly the evolution of thick oxide scales on dendritic regions of the Co-rich alloy (Figures 11(a) and 12). Additionally, selected maps for ERBOCo-1X-D (Figures 11(b) and 13) which remarkably differ from the findings presented for the Co-base multinary alloy are provided.

Obviously, the outer oxide layer that developed on dendritic regions of ERBOCo-1 (Figure 12) is composed of $\mathrm{Co}, \mathrm{Ni}$, and oxygen. As expected, the ratio of $\mathrm{Co}$ to $\mathrm{Ni}$ within this layer qualitatively correlates to the inherent ratio defined by the alloy. Underneath the outer oxide scale, a complex inner oxide zone is present.

Accessing the sequence of protective scale formation is complex for the Co-base alloy. The micrographs demonstrate three laterally aligned $\mathrm{Cr}$-enriched regions (Figure 12). Whereas the upper two are strongly pronounced and resemble actual layers, the innermost zone is made up of several distinct spots at which only a weak $\mathrm{Cr}$ signal is recognizable. In the case of samples with higher $\mathrm{Ni}$ levels, only 2 layers that are apparently dominated by noticeable $\mathrm{Cr}$ and $\mathrm{O}$ amounts can be detected (Figure 13). A similar trend can be recognized for alumina formation, as also the $\mathrm{Al}$ maps indicate a more abrupt and sustainable growth of alumina in case of ERBOCo-1X. It is noteworthy, however, that in the case of ERBOCo-1X, no laterally closed alumina scale grew within the dendritic regions. In theory, $\mathrm{SiO}_{2}$ would be another protective oxide. Due to the relatively low $\mathrm{Si}$ content $(0.4$ at. pct), no layer formation can be recognized. This means that besides some discrete spots, ${ }^{[54]}$ the $\mathrm{Si}$ enrichment only correlates with the $\mathrm{Cr}$, Ta, and Ti maps to a minor extent and is therefore not provided for ERBOCo-1X.

Regarding the distribution of refractory metals, it is noteworthy that in the case of ERBOCo-1, a more pronounced enrichment of $\mathrm{W}$ within the oxide scale is apparent. Firstly, a hemline-like layer directly beneath the $\mathrm{Co} / \mathrm{Ni}$-oxide scale into which discrete $\mathrm{W}$-rich oxide particles are embedded is allocated (Figure 12). These 
ERBOCO-1-D

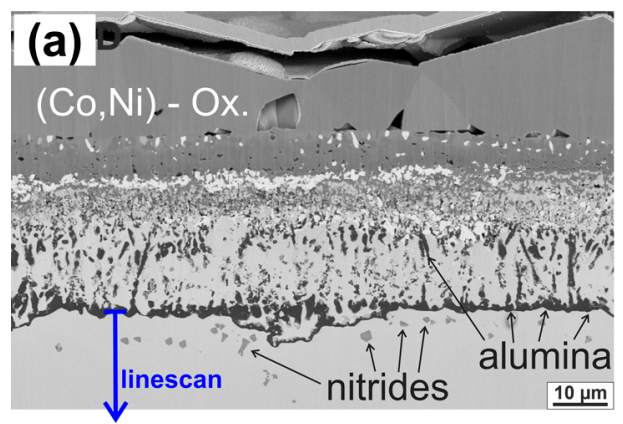

ERBOCo-1X-D

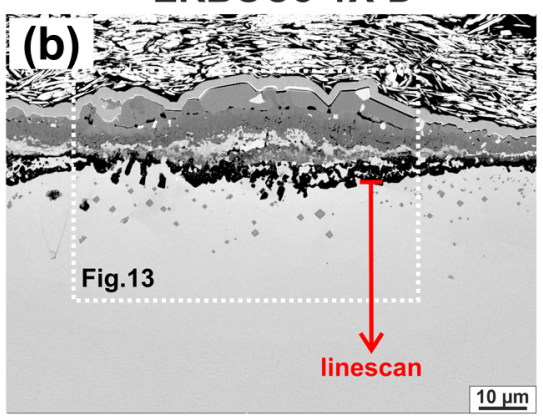

ERBOCo-1-ID

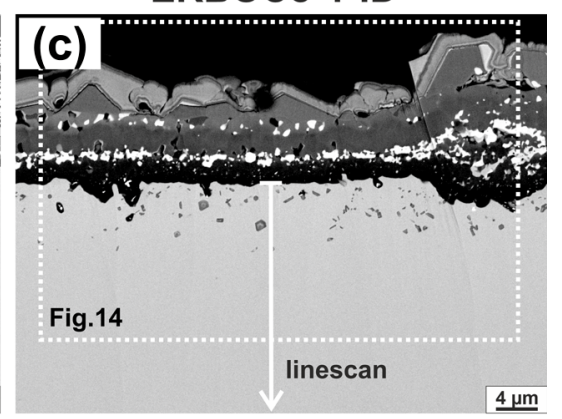

Fig. 11-BSE micrographs of HTS samples subsequent to oxidation for $100 \mathrm{~h}$ at $1050{ }^{\circ} \mathrm{C}$. (a) Depicts a dendritic (thick) spot of ERBOCo-1, whereas $(b)$ refers to a dendritic (thick) spot of ERBOCo-1-X. Finally, $(c)$ shows an interdendritic (thin) spot of ERBOCo-1. Corresponding elemental distribution maps were determined by EPMA and are provided in Fig. 12 for micrograph (a), in Fig. 13 for enframed area of micrograph (b), and in Fig. 14 for enframed area of micrograph (c). The arrows depict the position of the linescans that are provided in Fig. 15.

\section{ERBOCO-1-D}
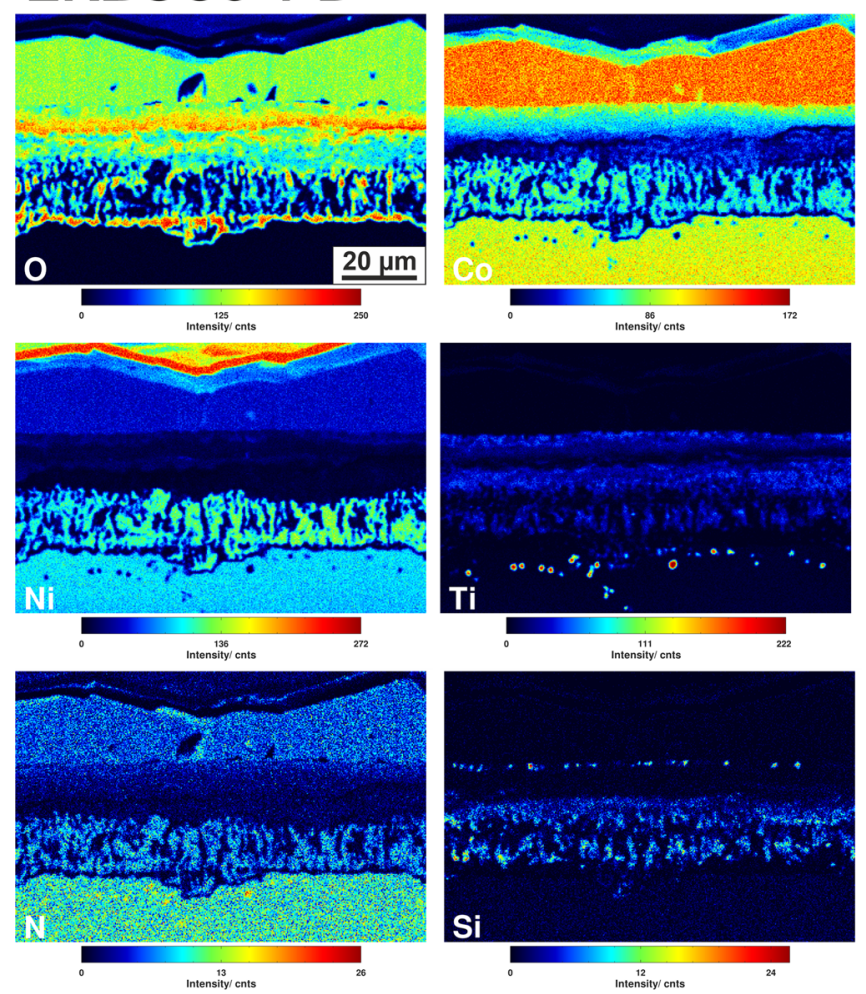

Fig. 12-Elemental distribution maps of dendritic region of ERBOCo-1 EPMA. Respective BSE micrograph is depicted in Fig. 11a.

phases are most pronounced in ERBOCo-1. Secondly, within the IOZ, two additional zones that are rich in $\mathrm{W}$-containing oxide are depicted. In contrast, only a few discrete W-rich precipitates that are randomly distributed throughout the scale can be found for ERBOCo-1X (Figure 13). Consequently, the W enrichment below the oxide/metal interface (Figure 13) might be interpreted as the consequence of a reluctant $\mathrm{W}$-oxide formation, resulting into a displacement-driven transport of $\mathrm{W}$ into the adjacent region of the alloy.
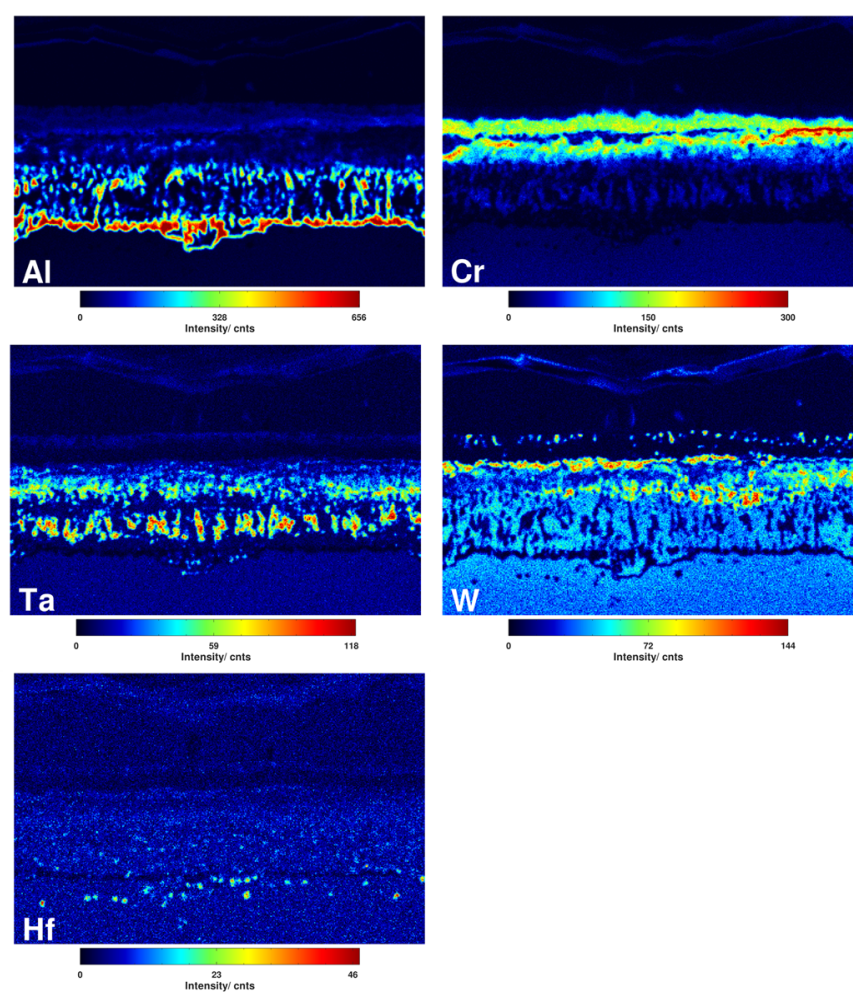

Furthermore, a correlation between the Ta and Ti maps is observed. A recent study on the oxidation of IN792 suggested that the two elements may form a diffusion-limiting phase $\left(\mathrm{TaTiO}_{4}\right)$ at $1050{ }^{\circ} \mathrm{C} .{ }^{[55]}$ However, the correlation of $\mathrm{Ta}$ and $\mathrm{Ti}$ maps is rather weak in the presented micrographs. This leaves doubts on the stoichiometric formation of a phase that was proposed in the cited study, in the case of the ERBOCo alloys. Similar to the oxidation at $850{ }^{\circ} \mathrm{C}$, nitrides can be found below the IOF. The latter are clearly enriched in $\mathrm{Hf}$ and $\mathrm{Ti}$ but not in $\mathrm{Al}$ what 


\section{ERBOCo-1X-D}
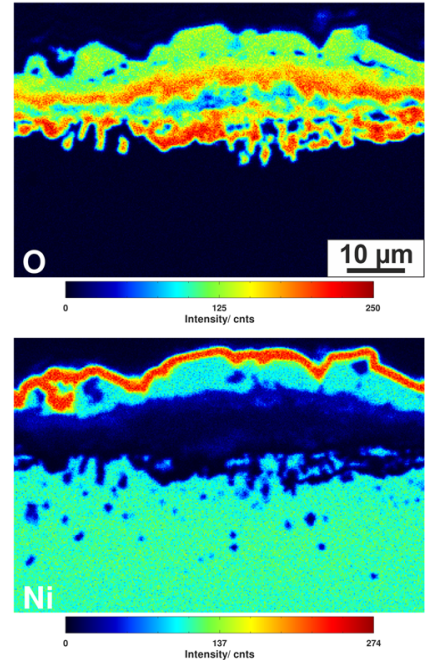
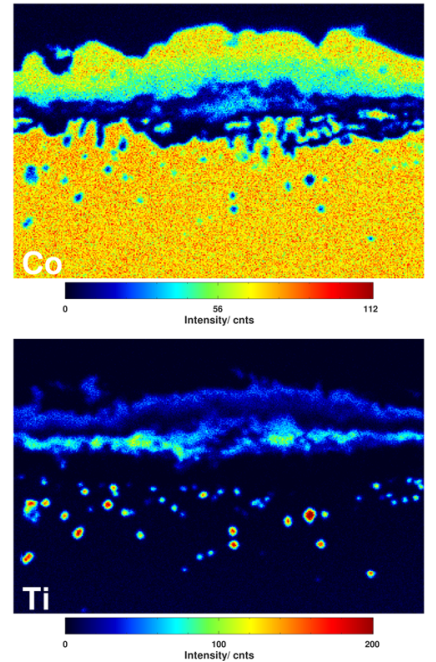
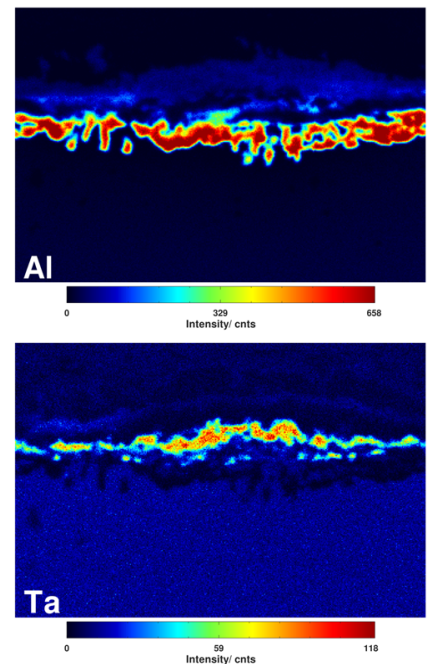
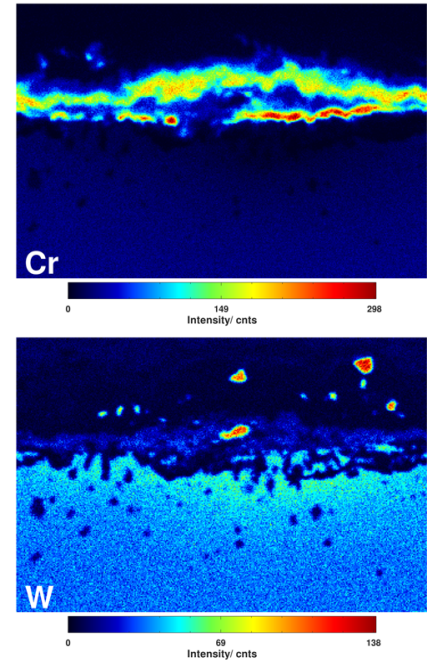

Fig. 13-Selected elemental distribution maps of dendritic region of ERBOCo-1-X (HTS) subsequent to $100 \mathrm{~h}$ of exposure at $1050{ }^{\circ} \mathrm{C}$ determined by EPMA. Respective BSE micrograph is depicted in Fig. 11b.

\section{ERBOCo-1-ID}
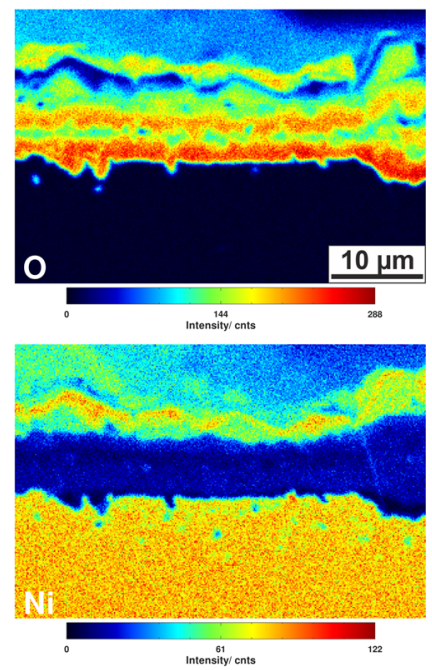
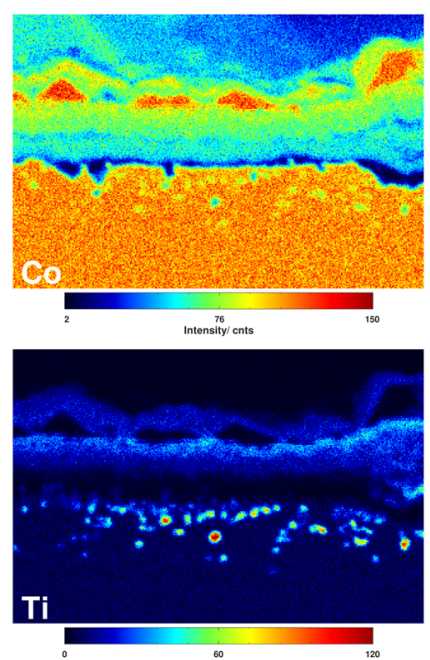

Intensity conts
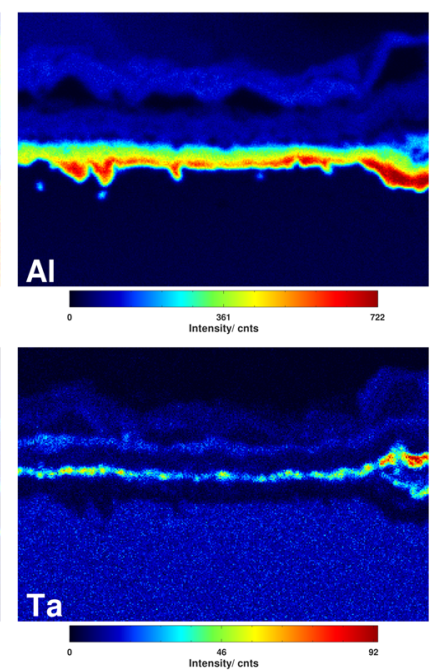
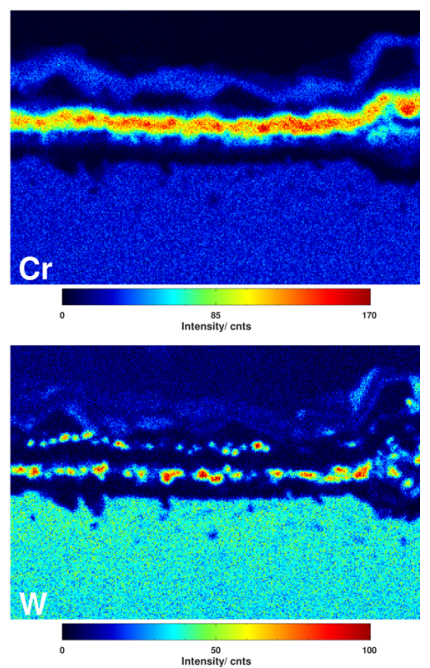

Fig. 14 -Selected elemental distribution maps of interdendritic region of ERBOCo-1 (HTS) subsequent to 100 -h exposure at $1050{ }^{\circ} \mathrm{C}$ determined by EPMA. Respective BSE micrograph is depicted in Fig. 11c.

matches well with the results from other groups that stated a higher thermodynamic stability of $\mathrm{HfN}$ and TiN as compared to AlN. ${ }^{[56,57]}$ Overall, the EPMA results of the dendritic regions reveal discontinuous protective oxide layers for both ERBOCo alloys (Figures 11(a) and (b), 12, and 13).

In the case of ERBOCo-1 (Figures 11(c) and 14), a much thinner outer oxide scale grew on interdendritic regions compared to the dendritic spot ( $\mathrm{Co} / \mathrm{Ni}$-oxide), indicating short stage of transient oxidation. Beneath, a layer mainly enriched in distinct W-rich oxides is present that could also be found for the oxide scale of the dendritic region (see Figure 12). The appearance of only one $\mathrm{Cr}$-enriched zone underneath this refractory metal-enriched layer (instead of three, see Figure 12) is a remarkable difference compared to the thick oxide spot. It is noteworthy that this region is free of discontinuities that could indicate a local breakdown of protective properties. Below the chromia scale, a layer significantly enriched in $\mathrm{Ta}$ and $\mathrm{W}$ is present (Figure 14). With respect to thermodynamic stability, $\mathrm{Ta}_{2} \mathrm{O}_{5}$ and $\mathrm{Ta}_{2} \mathrm{WO}_{8}$ can be expected to grow below the dissociation pressure of $\mathrm{Cr}_{2} \mathrm{O}_{3}{ }^{[58-60]}$ No Ti enrichment, as it was described for the thick spots on dendrite cores, can be identified in the Ta-containing layer. Therefore, at least for the interdendritic regions, the formation of $\mathrm{TaTiO}_{4}$ can be excluded in case of the ERBOCo system. ${ }^{[55]}$ Finally, along the IOF, a compact lateral alumina layer $(\mathrm{Al} / \mathrm{O} \sim 0.69$ determined from EPMA linescans) can be found. 


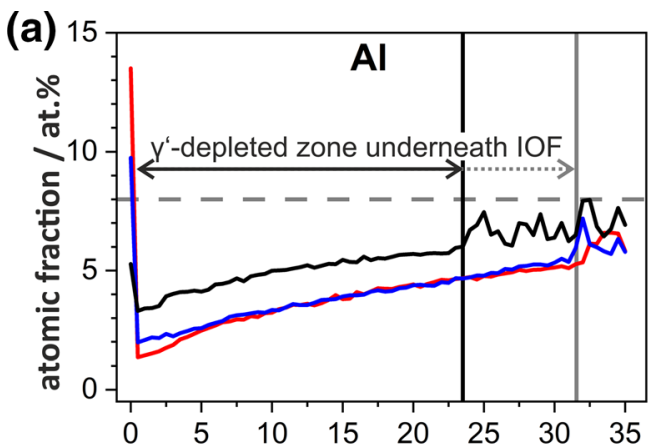

(b)
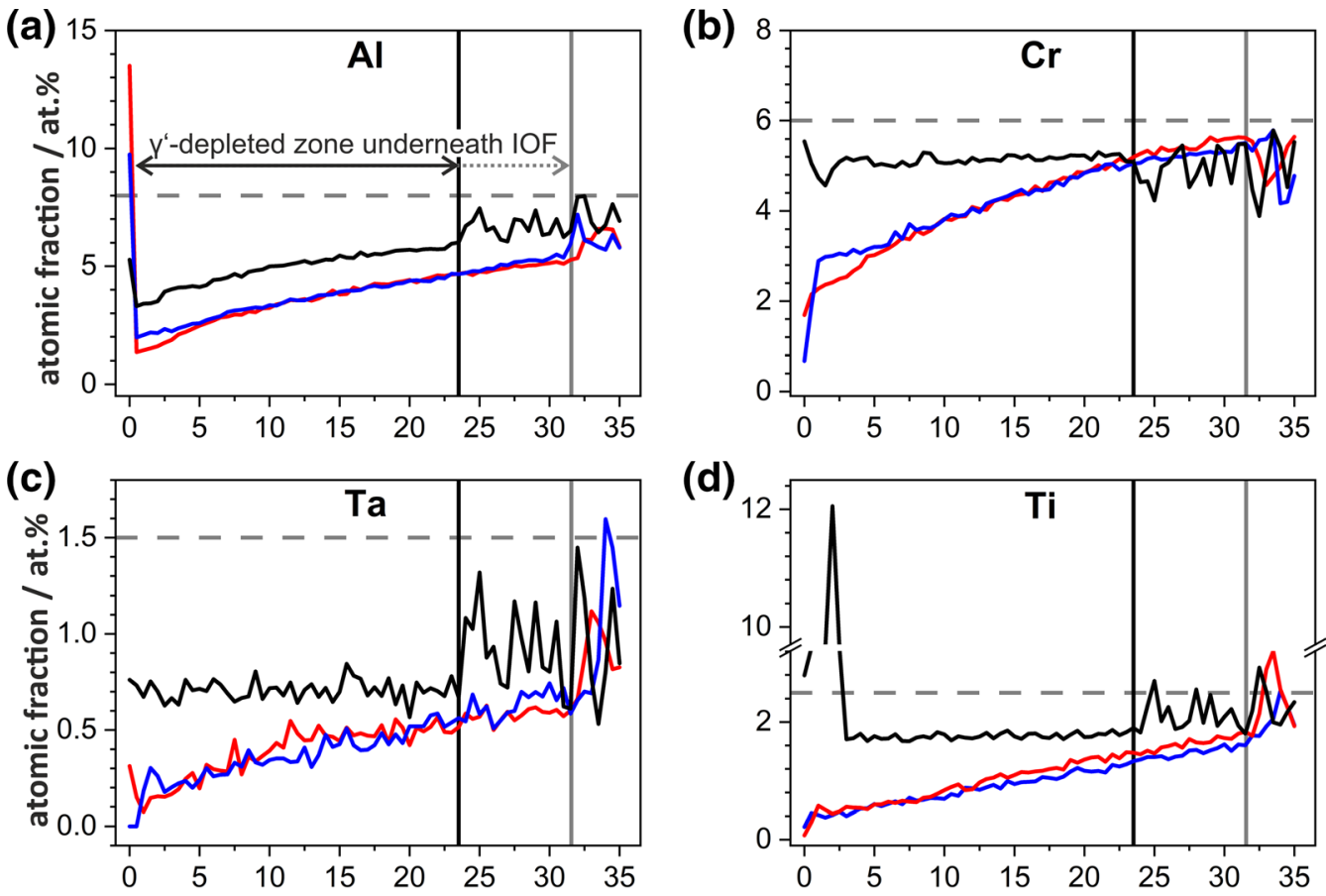

(d)
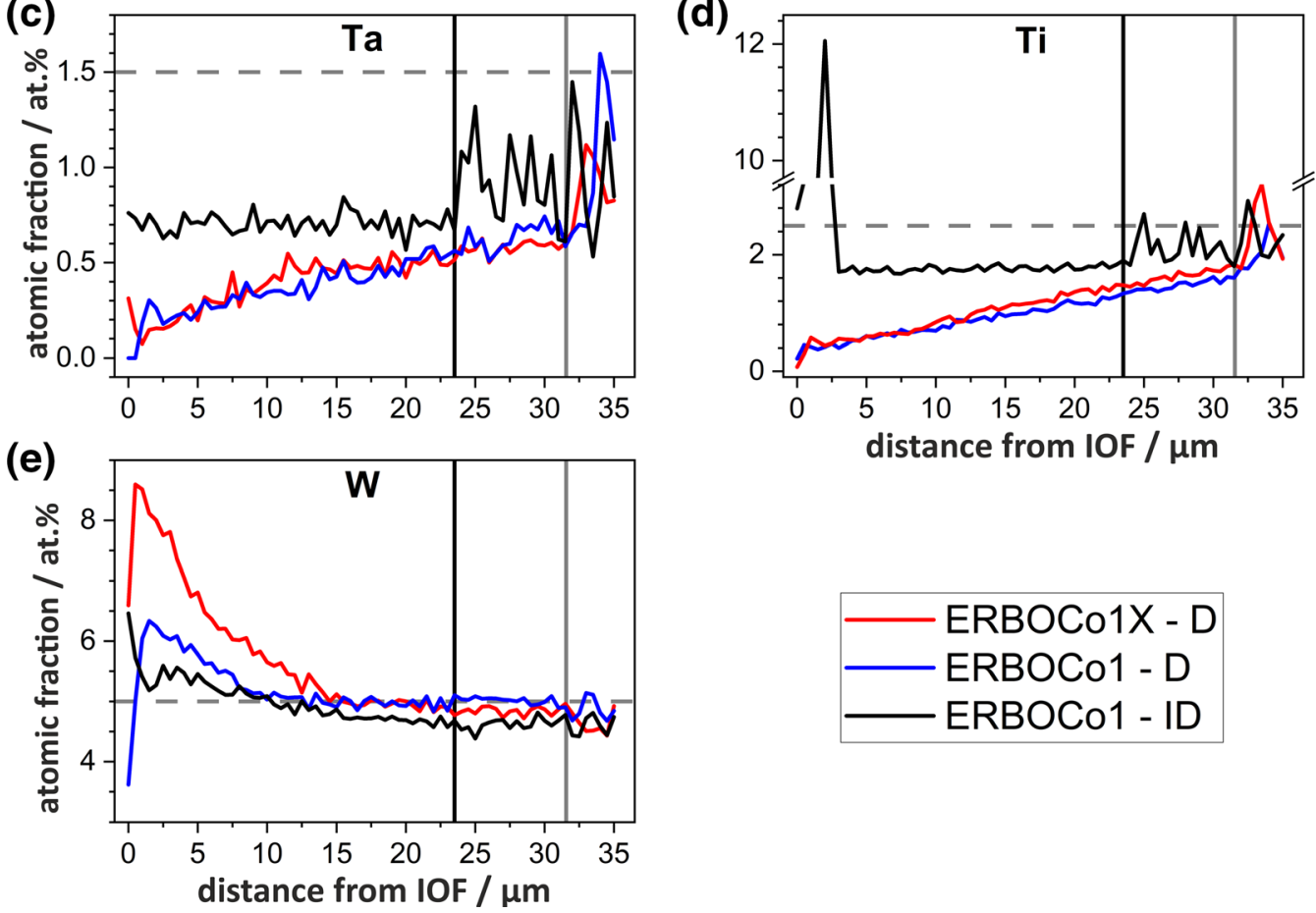

Fig. 15-Elemental concentrations within the $\gamma^{\prime}$-depleted zone beneath the IOF measured by EPMA for HTS samples oxidized for $100 \mathrm{~h}$ at $1050{ }^{\circ} \mathrm{C}$ with $(a)$ for $\mathrm{Al},(b)$ for $\mathrm{Cr},(c)$ for $\mathrm{Ta},(d)$ for $\mathrm{Ti}$, and $(e)$ for $\mathrm{W}$. The position of the linescans is highlighted by means of arrows in Fig. 11a for ERBOCo-1-D (blue), in Fig. 11b for ERBOCo-1X-D (red), and in Fig. 11c for ERBOCo-1-ID (black). The value of $0 \mu \mathrm{m}$ corresponds to the crossline of the arrows.

As demonstrated above, in HTS condition the residual solidification-induced compositional variations are sufficient to strongly affect the growth of protective oxides. To obtain quantitative information on the elemental distribution within the oxidation-affected regions of the alloys, additionally EPMA linescans are provided in Figure 15. The exact position of every scan is indicated by arrows within the BSE micrographs of Figure 11. Each diagram reveals the concentration gradient of one element between the alumina layer and the subjacent region of the IOF. Naturally, the position of the local minima in Al concentration $(x=0)$ coincides with the inner border of the alumina layer (see Figure 15(a)). For ERBOCo-1, two linescans are provided, one taken at dendritic (Figure 11(a), blue line) and the other at interdendritic (Figure 11(c), black line) positions. Additionally, data referring to the dendritic region of ERBOCo-1X (Figure 11(b), red line) are included. The nominal concentration of the individual elements is visualized by the use of dashed horizontal lines. For ERBOCo-1-ID, the position of the border between the $\gamma^{\prime}$-free zone and the $\gamma / \gamma^{\prime}$-strengthened substrate is represented via a black vertical line (exemplarily labeled in Figure 15(a)). Due to the inhomogeneous partitioning of the individual elements between both phases, ${ }^{[24]}$ beyond this position-i.e., within the $\gamma /$ $\gamma^{\prime}$-hardened substrate-pronounced alterations within the curves can be recognized. The positions of the aforementioned borderlines almost coincide for dendritic spots. Therefore, solely a single vertical line (gray) was added to the graph.

Focusing on the $\mathrm{Al}$ (Figure 15(a)) and $\mathrm{Cr}$ distribution (Figure 15(b)), beneath the thick oxide spots of ERBOCo-1 (blue) and ERBOCo-1X (red), a pronounced depletion of both elements is obvious. It is noteworthy that slightly higher values in the proximity of the IOF are observed (especially noticeable for $\mathrm{Cr}$ in Figure 15(b)) for the Co-base alloys. This might be a 
consequence of the locally continuous alumina layer that grew along the IOF in the case of ERBOCo-1, only (see Figures 11(a) and 12). It should be emphasized that this layer is not sustainable during longer exposure times, as Figures 10(i) and (j) indicate. Comparing the two linescans that are provided for ERBOCo-1 (blue: D and black: ID), apparently less severe depletion of $\mathrm{Cr}$ and $\mathrm{Al}$ can be recognized in the case of the interdendritic position. According to Figure 15(b), an almost unaltered $\mathrm{Cr}$ concentration within the $\gamma$-phase is remarkable (the local minimum in IOF proximity can be attributed to nitride formation, see Figure 15(d)). The apparent differences in depletion together with the smaller oxide thickness indicate an overall lower consumption of $\mathrm{Al}$ and $\mathrm{Cr}$ within the interdendritic region. Therefore, an earlier termination of the transient oxidation stage is causative. Also, the growth rate of the chromia layer, which apparently formed according to Figure 14, can be expected to be significantly decreased with the formation of a continuous alumina barrier layer beneath. Therefore, the $\mathrm{Cr}$ flux originated by the substrate is sufficient to counterbalance the $\mathrm{Cr}$ depletion along the IOF/alloy interface. It is concluded that at the interdendritic sample spots a similar mechanism is operative for $\mathrm{Ta}$ and $\mathrm{Ti}$ (see Figures 15(c) and (d)). Obviously, the consumption of the latter is strongly hindered through the blocking effect of the lateral alumina scale (see Figure 14). If no continuous alumina scale formed (see Figure 13 for ERBOCo-1X-D), or if the latter grew after a pronounced period of massive internal oxidation (see Figure 12 for ERBOCo-1-D), an excessive incorporation of Ta and Ti into the IOZ cannot be hindered. This is indicated by the considerable depletion of $\mathrm{Ta}$ and $\mathrm{Ti}$ in IOF proximity, observed in the dendritic regions of both alloys, according to the linescans in Figures 15(c) and (d). Focusing on the $\mathrm{W}$ distribution, an enrichment within the $\gamma^{\prime}$-depleted zone is obvious. Clearly, the highest $\mathrm{W}$ contents prevail within close IOF proximity. This trend is more pronounced in the case of the dendritic spots and especially in the case of the Ni-base alloy. As the sum of all components is 100 pct, the W enrichment might be explained as a consequence of selective oxidation, hence by the depletion of other elements. This mechanism is substantiated by the low W levels that are incorporated within the oxide scales (especially in case of ERBOCo-1X, see Figure 13). As W diffuses slowly, consequently, a steep concentration gradient develops. However, in case of ERBOCo-1, W is clearly present within the oxide (see Figures 12 and 14). Chyrkin et al. investigated elemental subscale enrichments in the case of the Ni-base alloy 625, oxidized at $900{ }^{\circ} \mathrm{C}$ and $1000{ }^{\circ} \mathrm{C}$. ${ }^{[61]}$ It was found that due to a decreased $\mathrm{Cr}$ concentration within IOF proximity, $\mathrm{Nb}$-uphill diffusion from the subjacent alloy towards the Cr-depletion zone was initiated. Jalowicka et al. described this effect also for $\mathrm{W}$ in their study on the oxidation behavior of the $\mathrm{Ni}-\mathrm{Cr}-\mathrm{W}$ system. ${ }^{[62]}$ Even though no W depletion subjacent to the $\gamma^{\prime}$-free zone could be identified by means of EPMA linescans, a substantial W enrichment occurred for both ERBOCo alloys. The results of Chyrkin et al. ${ }^{[61]}$ are still noteworthy, as they demonstrate that a reduction of the chemical potential of $\mathrm{W}$ further stabilizes the $\mathrm{W}$ enrichment at the IOF.

The presented EPMA results demonstrate that the residual elemental segregations (HTS) that prevail at the dendrite cores are sufficient to locally retard the formation of sustainable and protective oxide layers within the scales. This leads to highly localized and severe oxidation-induced material degradation. The linescans furthermore indicate that local compositional differences can be explained by a complex interplay of the advancing oxidation front and protective scale growth. The enrichment of $\mathrm{W}$ in proximity of the IOF is remarkable, as this element is known to negatively affect protective scale formation, presumably by decelerating the diffusivity of protective scale formers, e.g., Al and $\mathrm{Cr}$. $\left.{ }^{[44} 48\right]$ Therefore, the driving force for a transition from internal oxidation to continuous protective scale growth can be expected to be further decreased within dendritic regions over time.

\section{Oxidation Resistance with Respect to CMSX-4}

Since the main focus of the current study lies on the ERBOCo system, the oxidation behavior of the commercial Ni-base superalloy is considered separately. For exposure durations exceeding $40 \mathrm{~h}$, the $\mathrm{TG}$ analysis at $850{ }^{\circ} \mathrm{C}$ (see Figure 4) revealed a higher mass gain of CMSX-4 compared to both ERBOCo alloys after short heat treatment (HTS). This difference is also represented in the scale thickness values that are directly provided in the micrographs of the displayed oxide scales (Figures 5(b), (d), (f), and (h) with Figures 16(a) and (b)). Similar to the ERBOCo system, the dendritic regions of CMSX-4 are especially prone to oxidation. ${ }^{[20]}$
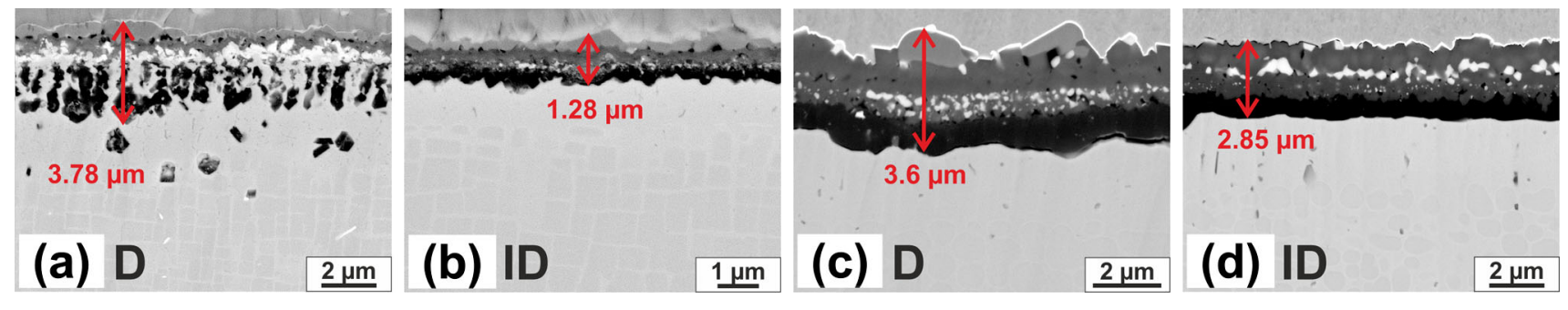

Fig. 16-BSE micrographs of cross sections of CMSX-4 after $100 \mathrm{~h}$ of exposure at $850{ }^{\circ} \mathrm{C}(a$ and $b)$ and $1050{ }^{\circ} \mathrm{C}(c$ and $d)$. The micrographs depict representative scale spots for dendritic ( $a$ and $c$ ) and interdendritic (b and d) regions. The red arrows indicate the max. thicknesses on hand at the depicted spots. 
Therefore, formation of compact alumina scales can be excluded (Figure 16(a)). ${ }^{[18,20,32,63,64]}$ The representative scale thickness value at the dendritic region of CMSX-4 surpasses ERBOCo-1X-HTS $(2.7 \mu \mathrm{m})$ and ERBOCo-1-HTS $(2.58 \mu \mathrm{m})$. In contrast, selected interdendritic regions revealed lateral alumina growth (Figure 16(b)). However, also at these interdendritic sites the thinnest oxide scales were found for ERBOCo-1. Even though the results indicate a beneficial impact of high Co levels at $850{ }^{\circ} \mathrm{C}$, it needs to be mentioned clearly that no statistical investigation was conducted (as for $1050{ }^{\circ} \mathrm{C}$ ) and, therefore, the absolute values provided within the micrographs need to be interpreted with caution.

To allow a conservative comparison, for the results at $1050{ }^{\circ} \mathrm{C}$ the discussion is focused on ERBOCo alloys in HTL state (long heat treatment) only. In contrast to $850{ }^{\circ} \mathrm{C}$, significantly slower oxidation kinetics were recorded for CMSX-4 at $1050{ }^{\circ} \mathrm{C}$ for the entire duration of the TG analysis. The higher oxidation resistance of CMSX-4 is also represented by an overall lower mass gain of $0.4 \mathrm{mg} / \mathrm{cm}^{2}$ compared to ERBOCo-1-HTL (3.37 $\mathrm{mg} / \mathrm{cm}^{2}$ ) and ERBOCo-1X-HTL (1.63 mg/ $\left.\mathrm{cm}^{2}\right)$, respectively. Analysis of cross sections demonstrates comparable thickness for scales grown on dendritic and interdendritic regions (Figures 16(c) and (d)) during exposure at $1050{ }^{\circ} \mathrm{C}$. The representative value of the thin spot $(2.85 \mu \mathrm{m})$ lies below the respective thickness of ERBOCo-1-HTL (median: $4.83 \mu \mathrm{m}$ ) and ERBOCo-1X-HTL (median: $3.45 \mu \mathrm{m}$ ). Deviations of the overall scale thickness on dendritic regions of CMSX-4 $(3.6 \mu \mathrm{m})$ and the thick spots of oxide scales on ERBOCo-1-HTL (median: $41.3 \mu \mathrm{m}$ ) and ERBOCo-1X-HTL (median: $20 \mu \mathrm{m}$ ) are considerably larger. Furthermore, for CMSX-4 a compact and continuous alumina scale formed on the entire sample, whereas fast internal oxidation lead to massive oxide thicknesses of both ERBOCo alloys.

Overall, the comparison to CMSX-4 indicates that the unsatisfying oxidation resistance of both ERBOCo alloys at $1050{ }^{\circ} \mathrm{C}$ is most apparent in thick oxide scales that develop in distinct regions of the sample due to compositional inhomogeneities. Even though the heat treatments unequivocally exhibit a positive impact on oxidation resistance, they were insufficient to ensure the formation of a homogeneous oxide scale. Whereas the oxidation resistance of both ERBOCo alloys at $850{ }^{\circ} \mathrm{C}$ is promising, massive oxide growth at the dendritic sites was identified as a severe problem for the use in the high-temperature regime.

\section{SUMMARY AND CONCLUSIONS}

The high-temperature oxidation behavior of two novel single-crystalline $\gamma / \gamma^{\prime}$-strengthened multinary superalloys, ERBOCo-1 (Co/Ni ratio: 1.4) and ERBO$\mathrm{Co}-1 \mathrm{X}(\mathrm{Co} / \mathrm{Ni}$ ratio: 0.7$)$, was elucidated in detail. The nominal content of alloying elements (Al, Cr, W, Ti, Ta, $\mathrm{Si}$, and $\mathrm{Hf}$ ) remained unaltered in the investigated model alloys. Thermogravimetry and the extensive analysis of cross sections as well as the comparison with the oxidation behavior of a commercial Ni-base Superalloy (CMSX-4) lead to the following conclusions:

- For the ERBOCo alloys, Co, Cr, and W enrich within the dendrite cores, whereas all other elements enrich within the interdendritic regions.

- TG analyses revealed a positive impact of high Co levels at $850{ }^{\circ} \mathrm{C}$. Accordingly, at this temperature ERBOCo-1 performed slightly better than ERBOCo-1X and the highest mass gain was recorded for CMSX-4. In contrast, a superior oxidation resistance was found for CMSX-4 at $1050{ }^{\circ} \mathrm{C}$, followed by ERBOCo-1X and finally by ERBOCo- 1 .

- At both exposure temperatures the dendritic composition of the ERBOCo alloys was especially prone to the formation of thick oxide scales, as insufficient lateral alumina growth could not prevent inward oxygen penetration. Internal oxidation of CMSX-4 was only exhibited at $850{ }^{\circ} \mathrm{C}$. At higher temperature also the dendritic spots of CMSX-4 were sufficiently protected through the fast formation of diffusion-limiting alumina.

- For all three alloys, enhanced alumina formation is observed at the interdendritic sites leading to clearly thinner oxide scales.

- At $1050{ }^{\circ} \mathrm{C}$, significant scattering in oxide thicknesses was found for ERBOCo-1 and ERBOCo-1X. By far the most homogeneous scales grew on CMSX-4. Samples of increased homogeneity (accessible via different heat treatments prior to oxidation) exhibited smaller scale thicknesses compared to specimens in the as-cast state. This effect was especially pronounced for dendritic regions but also recognizable for the interdendritic sites.

- Accordingly, TGA results also indicated a beneficial influence of homogenization annealing prior to exposure. After homogenization annealing, the interdendritic scale thickness of both ERBOCo alloys could be decreased to values in the order of CMSX-4. However, even a prolonged homogenization annealing ( $>100$ hours) prior to exposure was insufficient to fully overcome the undesirable formation of non-protective scale sections.

Overall, both ERBOCo alloys performed better than the commercial second-generation Ni-base alloy at $850{ }^{\circ} \mathrm{C}$. At $1050{ }^{\circ} \mathrm{C}$ high mass-gain rates are caused by dendritic segregations. We therefore conclude that future alloy development activities of Co-rich superalloys should especially focus on the $\mathrm{W}$ content, as this element strongly enriches within the dendrite cores during solidification and as it cannot easily be redistributed through annealing within reasonable durations.

\section{ACKNOWLEDGMENTS}

Scientific and financial support by the Deutsche Forschungsgemeinschaft (DFG) through the Collaborative Research Center SFB-TR 103 (Project A5) is highly acknowledged. The authors would like to 
express their gratitude to Gerald Schmidt and Mathias Galetz as well as Tobias Gaag and Christopher Zenk for conducting the EPMA measurements and the helpful discussions.

\section{FUNDING}

Open Access funding enabled and organized by Projekt DEAL.

\section{CONFLICT OF INTEREST}

On behalf of all authors, the corresponding author states that there is no conflict of interest.

\section{OPEN ACCESS}

This article is licensed under a Creative Commons Attribution 4.0 International License, which permits use, sharing, adaptation, distribution and reproduction in any medium or format, as long as you give appropriate credit to the original author(s) and the source, provide a link to the Creative Commons licence, and indicate if changes were made. The images or other third party material in this article are included in the article's Creative Commons licence, unless indicated otherwise in a credit line to the material. If material is not included in the article's Creative Commons licence and your intended use is not permitted by statutory regulation or exceeds the permitted use, you will need to obtain permission directly from the copyright holder. To view a copy of this licence, visit http://creat ivecommons.org/licenses/by/4.0/. 


\section{APPENDIX}

EPMA Maps for ERBOCo-1-AC

See Figure A1

\section{Thickness Measurements}

Figure A2(a) exemplarily shows an ion-milling cut on an oxidized AC sample in BSE contrast. Obviously, bright-appearing dendrites can be recognized in through-thickness direction. In both, AC and HTS sample states, only spots that could be clearly assigned to either dendritic or interdendritic regions were considered for thickness measurements. Examples of allocated sample regions are indicated by arrows in Figure A2(a) (red: thick spots; black: thin spots).

Figure A2(b) shows an interdendritic scale spot in higher magnification. Obviously, a pronounced scatter in scale thickness prevailed. It was decided to measure
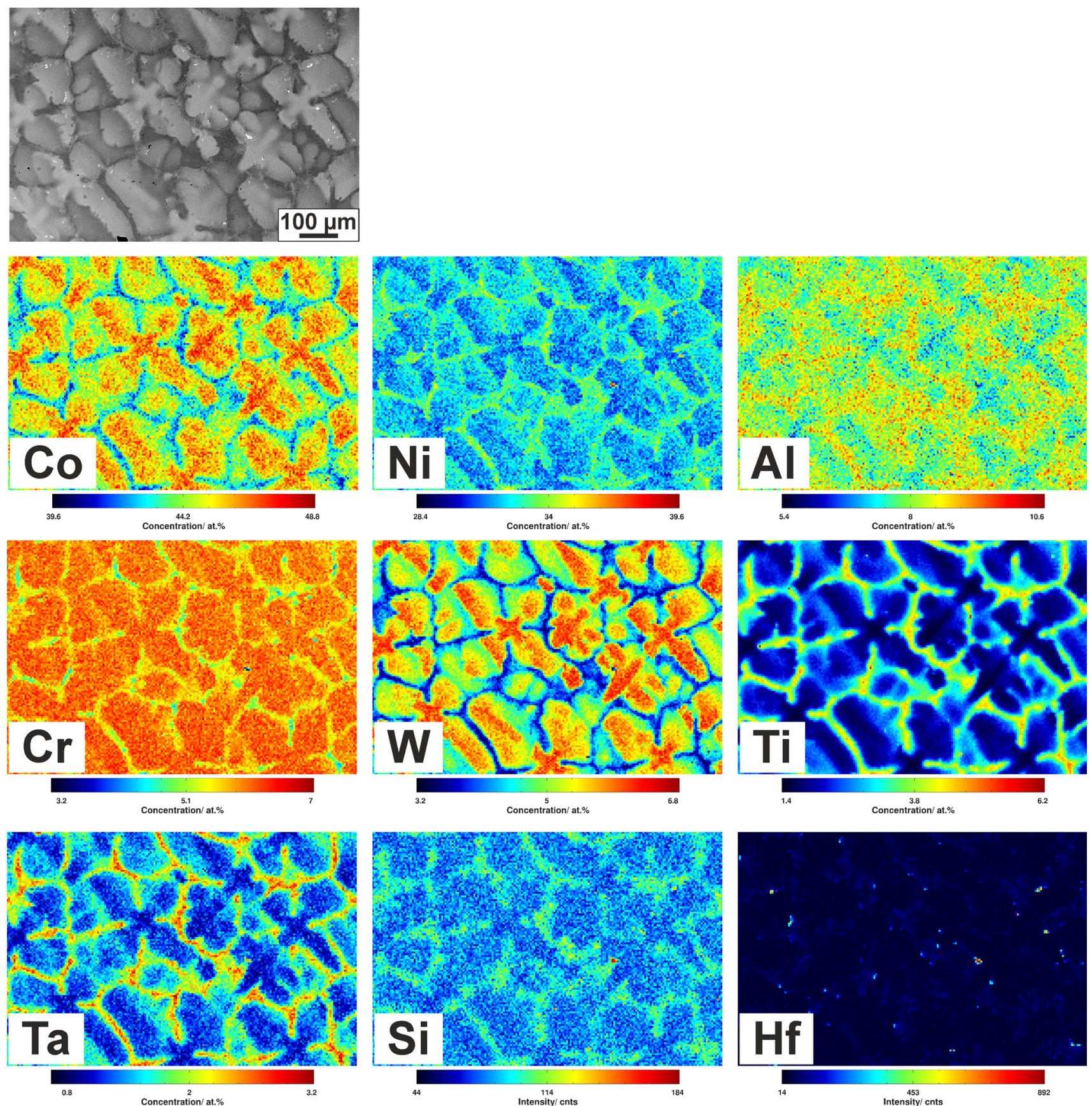

Fig. A1-BSE micrograph and corresponding elemental distribution maps determined by EPMA for ERBOCo-1 in AC state. Color coding shows elemental concentrations in at. pct for $\mathrm{Co}, \mathrm{Ni}, \mathrm{Al}, \mathrm{Cr}, \mathrm{W}, \mathrm{Ti}$, and $\mathrm{Ta}$ (sum of the latter equaling 100 at. pct). As the software did not allow a quantification in case of $\mathrm{Si}$ (nominal concentration of 0.4 at. pet) and $\mathrm{Hf}(0.1$ at. pet), solely qualitative plots representing the intensity are depicted, instead. 

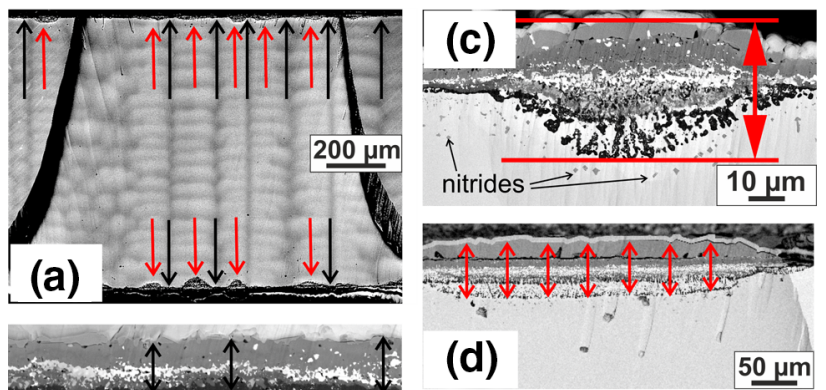

(b)

$5 \underline{\mu m}$

Fig. A2-Information on thickness measurements. (a) Ion-milling cut across mechanically pre-polished cross section of ERBOCo-1-AC with low magnification. Red arrows indicating dendritic, black indicating interdendritic scale sections. $(b)$ Interdendritic scale and typical thickness measurements. (c) Dendritic scale. (d) dendritic scale of HTL sample.

the local minima, as indicated by the 3 black arrows instead of determining the average thickness.

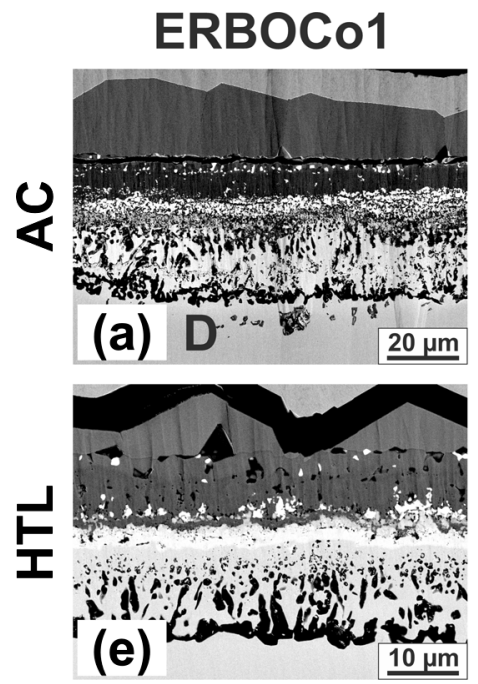

The same applies for the thick spots of samples in AC and HTS state where only extreme values (maxima) were measured. Consequently, solely one value was determined for each dendritic core (Figure A2(c)).

Figure A2(d) depicts a typical thick spot of a HTL sample. Since the lateral expansion of these (thick) scale spots is considerably larger than its thickness, more than one value was taken. Additionally, a constant distance in the range of the total scale thickness was kept between each measuring locations.

Representative Cross Sections for Both ERBOCo Alloys in $A C$ and HTL State After Oxidation for $100 \mathrm{~h}$ at $1050{ }^{\circ} \mathrm{C}$ in Synthetic Air

See Figure A3

Fig. A3-BSE micrographs of thick $(a, b, e$, and $f)$ and thin $(c, d, g$, and $h)$ spots of ERBOCo-1 and ERBOCo-1X. The alloys were either in AC state $(\mathrm{a}, \mathrm{b}, \mathrm{c}$, and $\mathrm{d})$, or in HTL state (e, f, g, and $\mathrm{h})$ prior to exposure. 


\section{REFERENCES}

1. N. Volz, C.H. Zenk, R. Cherukuri, T. Kalfhaus, M. Weiser, S.K. Makineni, C. Betzing, M. Lenz, B. Gault, S.G. Fries, J. Schreuer, R. Vaßen, S. Virtanen, D. Raabe, E. Spiecker, S. Neumeier, and M. Göken: Metall. Mater. Trans. A., 2018, vol. 49A, pp. 4099-4109. https://doi.org/10.1007/s11661-018-4705-1.

2. M. Lenz, Y.M. Eggeler, J. Müller, C.H. Zenk, N. Volz, P. Wollgramm, G. Eggeler, S. Neumeier, M. Göken, and E. Spiecker: Acta Mater., 2019, vol. 166, pp. 597-610. https://doi.org/10.1016/ j.actamat.2018.12.053.

3. J. Sato, T. Omori, K. Oikawa, I. Ohnuma, R. Kainuma, and K. Ishida: Science., 2006, vol. 312, pp. 90-91. https://doi.org/10.1126/ science. 1121738.

4. K. Shinagawa, T. Omori, J. Sato, K. Oikawa, I. Ohnuma, R. Kainuma, and K. Ishida: Mater. Trans., 2008, vol. 49, pp. 1474-79. https://doi.org/10.2320/matertrans.MER2008073.

5. S. Neumeier, L.P. Freund, and M. Göken: Scripta Mater., 2015, vol. 109, pp. 104-07. https://doi.org/10.1016/j.scriptamat.2015.07. 030.

6. C.H. Zenk, S. Neumeier, N.M. Engl, S.G. Fries, O. Dolotko, M. Weiser, S. Virtanen, and M. Göken: Scripta Mater., 2016, vol. 112, pp. 83-86. https://doi.org/10.1002/9781119075646.ch103.

7. E.A. Lass, D.J. Sauza, D.C. Dunand, and D.N. Seidman: Acta Mater., 2018, vol. 147, pp. 284-95. https://doi.org/10.1016/j.acta mat.2018.01.034.

8. C.A. Stewart, S.P. Murray, A. Suzuki, T.M. Pollock, and C.G. Levi: Mater. Des., 2020, vol. 189, p. 108445. https://doi.org/10. 1016/j.matdes.2019.108445.

9. M. Weiser and S. Virtanen: Oxid. Met., 2019, vol. 92, pp. 541-60. https://doi.org/10.1007/s11085-019-09934-w.

10. S.P. Hagen, M. Weiser, D. Kubacka, E. Spiecker, and S. Virtanen: Oxid. Met., 2020, vol. 94, pp. 477-503. https://doi.org/10.1007/ s11085-020-10003-w.

11. M. Weiser, M.C. Galetz, H.-E. Zschau, C.H. Zenk, S. Neumeier, M. Göken, and S. Virtanen: Corros. Sci., 2019, vol. 156, pp. 84-95.

12. M. Weiser, M.C. Galetz, R.J. Chater, and S. Virtanen: J. Electrochem. Soc., 2020, vol. 167, p. 21504. https://doi.org/10.1149/ 1945-7111/ab69f7.

13. C.A. Stewart, A. Suzuki, R.K. Rhein, T.M. Pollock, and C.G. Levi: Metall. Mater. Trans. A., 2019, vol. 50A, pp. 5445-58. h ttps://doi.org/10.1007/s11661-019-05413-8.

14. S.C.H. Llewelyn, R.J. Chater, N.G. Jones, M.C. Hardy, and H.J. Stone: Corros. Sci., 2021, vol. 178, p. 109087. https://doi.org/10. 1016/j.corsci.2020.109087.

15. F.H. Stott, G.C. Wood, and J. Stringer: Oxid. Met., 1995, vol. 44, pp. 113-45. https://doi.org/10.1007/BF01046725.

16. B.A. Pint, J.R. DiStefano, and I.G. Wright: Mater.Sci. Eng. A., 2006, vol. 415, pp. 255-63. https://doi.org/10.1016/j.msea.2005.09.091.

17. H. Hindam and D.P. Whittle: Oxid. Met., 1982, vol. 18, pp. 245-84. https://doi.org/10.1007/BF00656571.

18. C.M. Younes, G.C. Allen, and J.A. Nicholson: Corros. Eng. Sci. Technol., 2007, vol. 42, pp. 80-88. https://doi.org/10.1179/ $174327807 X 159925$.

19. A. Jalowicka, W.J. Nowak, D. Naumenko, and W.J. Quadakkers: JOM., 2016, vol. 68, pp. 2776-85. https://doi.org/10.1007/S11837016-2072-1.

20. J. Pistor, S.P. Hagen, S. Virtanen, and C. Körner: Scripta Mater., 2022, vol. 207, p. 114301. https://doi.org/10.1016/j.scriptamat.20 21.114301.

21. B. Gao, L. Wang, Y. Liu, X. Song, S.Y. Yang, and A. Chiba: Corros. Sci., 2019, vol. 157, pp. 109-15. https://doi.org/10.1016/j.c orsci.2019.05.036.

22. B.R. Goodlet, S.P. Murray, B. Bales, J. Rossin, C.J. Torbet, and T.M. Pollock: Mater. Sci. Eng. A., 2021, vol. 803, p. 140507. h ttps://doi.org/10.1016/j.msea.2020.140507.

23. B.R. Goodlet, B. Bales, and T.M. Pollock: Ultrasonics., 2021, vol. 115, p. 106455. https://doi.org/10.1016/j.ultras.2021.106455.

24. C.H. Zenk, N. Volz, C. Zenk, P.J. Felfer, and S. Neumeier: Curr. Comput.-Aided Drug Des., 2020, vol. 10, p. 1058. https://doi.org/ $10.3390 /$ cryst10111058.

25. D.E. Newbury and N.W.M. Ritchie: J. Mater. Sci., 2015, vol. 50, pp. 493-518. https://doi.org/10.1007/s10853-014-8685-2.

26. P. Malinovskis, S. Fritze, L. Riekehr, L. von Fieandt, J. Cedervall, D. Rehnlund, L. Nyholm, E. Lewin, and U. Jansson: Mater. Des., 2018, vol. 149, pp. 51-62. https://doi.org/10.1016/j.matdes.2018.03.068.
27. A.B. Parsa, P. Wollgramm, H. Buck, C. Somsen, A. Kostka, I. Povstugar, P.-P. Choi, D. Raabe, A. Dlouhy, J. Müller, E. Spiecker, K. Demtroder, J. Schreuer, K. Neuking, and G. Eggeler: Adv. Eng. Mater., 2015, vol. 17, pp. 216-30. https://doi.org/10. 1002/adem.201400136.

28. O.M. Horst, D. Adler, P. Git, H. Wang, J. Streitberger, M. Holtkamp, N. Jöns, R.F. Singer, C. Körner, and G. Eggeler: Mater. Des., 2020, vol. 195, p. 108976. https://doi.org/10.1016/j. matdes.2020.108976.

29. M. Karunaratne, D. Cox, P. Carter, and R. Reed: Superalloys., 2000, https://doi.org/10.7449/2000/Superalloys_2000_263_272.

30. A. Epishin, A. Chyrkin, G. Nolze, J. Midtlyng, H.M. Mayer, N. Petrushin, and W. Reimers: J. Phase Equilib. Diffus., 2018, vol. 39, pp. 176-85. https://doi.org/10.1007/S11669-018-0620-9.

31. S. Neumeier, H.U. Rehman, J. Neuner, C.H. Zenk, S. Michel, S. Schuwalow, J. Rogal, R. Drautz, and M. Göken: Acta Mater., 2016, vol. 106, pp. 304-12. https://doi.org/10.1016/j.actamat.2016. 01.028 .

32. A. Akhtar, M.S. Hook, and R.C. Reed: Metall. Mater. Trans. A., 2005, vol. 36A, pp. 3001-17. https://doi.org/10.1007/s11661-0050073-8.

33. Y. Hu, T. Cao, C. Cheng, L. Zhang, and J. Zhao: Appl. Surf. Sci., 2019, vol. 484, pp. 209-18. https://doi.org/10.1016/j.apsusc.2019. 04.089 .

34. M. Weiser, R.J. Chater, B.A. Shollock, and S. Virtanen: $n p j$ Mater. Degrad., 2019, vol. 3, p. 33. https://doi.org/10.1038/s41529019-0096-Z.

35. G. Hou, Y. An, X. Zhao, H. Zhou, and J. Chen: Acta Mater., 2015, vol. 95, pp. 164-75. https://doi.org/10.1016/j.actamat.2015. 05.025 .

36. W. Zhao, Y. Kang, J.M.A. Orozco, and B. Gleeson: Oxid. Met., 2015, vol. 83, pp. 187-201. https://doi.org/10.1007/s11085-014-95 16-1.

37. U. Krupp and H.-J. Christ: Metall. Mater. Trans. A., 2000, vol. 31A, pp. 47-56. https://doi.org/10.1007/s11661-000-0051-0.

38. M. Welker, A. Rahmel, and M. Schütze: Metall. Trans. A., 1989, vol. 20, pp. 1541-51. https://doi.org/10.1007/BF02665510.

39. S.Y. Chang, U. Krupp, and H.-J. Christ: Mater. Sci. Eng. A., 2001, vol. 301, pp. 196-206. https://doi.org/10.1016/S0921-5093(0 0)01670-1.

40. K. Tjokro and D.J. Young: Oxid. Met., 1995, vol. 44, pp. 453-74. https://doi.org/10.1007/BF01058247.

41. J. Dong, K. Sawada, K. Yokokawa, and F. Abe: Scripta Mater., 2001, vol. 44, pp. 2641-46. https://doi.org/10.1016/S1359-6462(01 )00953-8.

42. G.E. Fuchs and B.A. Boutwell: JOM., 2002, vol. 54, pp. 45-48. h ttps://doi.org/10.1007/BF02822605.

43. J.L. Smialek and G.H. Meier: Superalloys II-High Temperature Materials for Aerospace and Industrial Power, Wiley-Interscience, New York, 1987, pp. 293-326.

44. A. Sato, Y.-L. Chiu, and R.C. Reed: Acta Mater., 2011, vol. 59, pp. 225-40. https://doi.org/10.1016/j.actamat.2010.09.027.

45. G.H. Meier, F.S. Pettit, and A.S. Khan: High temperature oxidation of rapidly solidified Ni-Al-Mo-W Alloys, in Rapid Solidification Processing, Principles and Technologies, III. R. Mehrabian, ed., National Bureau of Standards, Gaithersburg, 1982, pp. $348-59$.

46. S. Espevik, R.A. Rapp, P.L. Daniel, and J.P. Hirth: Oxid. Met., 1983, vol. 20, pp. 37-65. https://doi.org/10.1007/BF00658126.

47. S. Espevik, R.A. Rapp, P.L. Daniel, and J.P. Hirth: Oxid. Met., 1980, vol. 14, pp. 85-108. https://doi.org/10.1007/BF00603987.

48. D. Kubacka, M. Weiser, and E. Spiecker: Corros. Sci., 2021, vol. 191, p. 109744. https://doi.org/10.1016/j.corsci.2021.109744.

49. T. Galiullin, A. Chyrkin, R. Pillai, R. Vassen, and W.J. Quadakkers: Surf. Coat. Technol., 2018, vol. 350, pp. 359-68. https://d oi.org/10.1016/j.surfcoat.2018.07.020.

50. C. Wagner: Zeitschrift für Elektrochemie, Berichte der Bunsengesellschaft für physikalische Chemie., 1959, vol. 63, pp. 772-82.

51. S.-J. Park, S.-M. Seo, Y.-S. Yoo, H.-W. Jeong, and H. Jang: Corros. Sci., 2015, vol. 90, pp. 305-12. https://doi.org/10.1016/j.c orsci.2014.10.025.

52. G.N. Irving, J. Stringer, and D.P. Whittle: Corros. Sci., 1975, vol. 15, pp. 337-44. https://doi.org/10.1016/S0010-938X(75)80015-1. 
53. H.T. Mallikarjuna, N.L. Richards, and W.F. Caley: J. Mater. Eng. Perform., 2017, vol. 26, pp. 2014-23. https://doi.org/10.1007/s116 65-017-2630-x.

54. A. Solimani, T. Nguyen, J. Zhang, D.J. Young, M. Schütze, and M.C. Galetz: Corros. Sci., 2020, vol. 176, p. 109023. https://doi. org/10.1016/j.corsci.2020.109023.

55. W.J. Nowak, B. Wierzba, and J. Sieniawski: High Temp. Mater. Process., 2018, vol. 37, pp. 801-06. https://doi.org/10.1515/htmp2017-0089.

56. R. Shu, dissertation, 2020. https://doi.org/10.3384/lic.diva-170529.

57. H.W. Chang, P.K. Huang, A. Davison, J.W. Yeh, C.H. Tsau, and C.C. Yang: Thin Solid Films., 2008, vol. 516, pp. 6402-08. https://d oi.org/10.1016/j.tsf.2008.01.019.

58. N.C. Stephenson and R.S. Roth: Acta Crystallogr. B., 1971, vol. 27, pp. 1010-17. https://doi.org/10.1107/S0567740871003388.

59. J. Wang, L. Yang, S. Yang, Y. Jia, M. Chen, Y. Qiao, P. Guo, S. Zhu, and F. Wang: Materials., 2021, vol. 14, p. 202. https://doi. org $/ 10.3390 / \mathrm{ma} 14010202$.
60. R.S. Roth: Prog. Solid State Chem., 1980, vol. 13, pp. 159-92. h ttps://doi.org/10.1016/0079-6786(80)90003-5.

61. A. Chyrkin, P. Huczkowski, V. Shemet, L. Singheiser, and W.J. Quadakkers: Oxid. Met., 2011, vol. 75, pp. 143-66. https://doi.org/ 10.1007/s11085-010-9225-3.

62. A. Jalowicka, R. Duan, P. Huczkowski, A. Chyrkin, D. Grüner, B.A. Pint, K.A. Unocic, and W.J. Quadakkers: JOM., 2015, vol. 67, pp. 2573-88. https://doi.org/10.1007/s11837-015-1645-8.

63. Md. Moniruzzaman, M. Maeda, Y. Murata, and M. Morinaga: ISIJ Int., 2003, vol. 43, pp. 386-93. https://doi.org/10.2355/isijinte rnational.43.386.

64. H.M. Tawancy: Oxid. Met., 2020, vol. 93, pp. 371-86. https://doi. org/10.1007/s11085-020-09960-z.

Publisher's Note Springer Nature remains neutral with regard to jurisdictional claims in published maps and institutional affiliations. 